\title{
The Relationship Between Value Orientation, Positive Moods and Perception of Fairness with internal auditors' Intention to Whistle-blowing
}

\author{
Mozhdeh Kadkhodaee Elyadarani \\ Ph.D Student of Accounting, Department of Accounting, Islamic Azad \\ University, Tehran Science and Research Branch, Tehran \\ (kadkhodaee.mojdeh@yahoo.com)
}

\author{
Bahman Banimahd* \\ Associate Professor of Accounting , Department of Accounting, Islamic Azad \\ University, Karaj Branch, Karaj(Corresponding Author), \\ dr.banimahd@gmail.com
}

\begin{abstract}
:
Value orientation is an important variable in work ethics that includes people's beliefs about material and post material issues. This study classifies internal auditors into three groups: materialistic, post materialist, and a combination of the two. Then, it measures the level of value orientation, positive moods and perception of fairness and examines its relation with the Whistle-blowing from a behavioral and social perspectives. In this Paper, the research method for collecting theoretical foundations is archival, also we use questionnaire for collecting survey data. The statistical sample of the present study includes 149 internal auditors working in listed companies on the Tehran stock exchange who have been selected by using the simple random sampling method. Multiple linear regression has been used to test the hypotheses. The results of hypotheses testing show that the value orientation has a significant and positive relationship with the materialistic internal auditors' intention to whistle-blowing. But this relationship is a significant and negative one in the post materialist auditing group. In the third group, materialist- post materialist internal auditors, there is no significant relationship between value orientation and whistle-blowing. Evidence of this study also shows that positive moods and fairness in all three groups have a significant and positive relationship with the whistle-blowing. The contribution of this research is the introduction of value orientation theory to behavioral accounting and auditing texts. The results of this study can also provide useful information to internal audit profession policymakers about fraud reporting.
\end{abstract}

Keywords: Internal Audit, Value Orientation, Positive Moods, Perception of Fairness and Whistle-blowing

Copyrights:

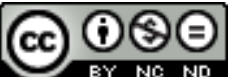

This license only allowing others to download your works and share them with others as long as they credit you, but they can't change them in any way or use them commercial. 


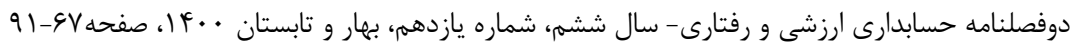

\section{رابطه جهت كيرى ارزشى، عواطف مثبت و درى از انصاف با تمايل حسابر سان داخلى بله كزار شكرى تقلب}

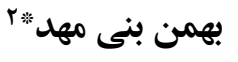

تاريخ هذيرش:99/IV

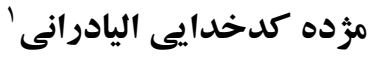

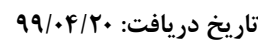

جكيده

جهت گيرى ارزشى، متغير با اهميتى در اخلاق كارى است كه شامل باورها و اعتقادات افراد

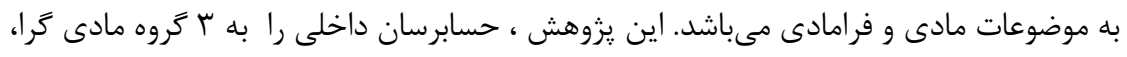

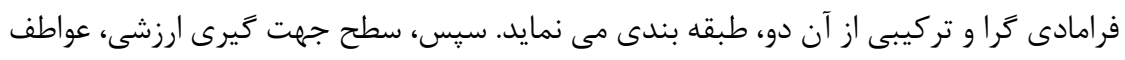

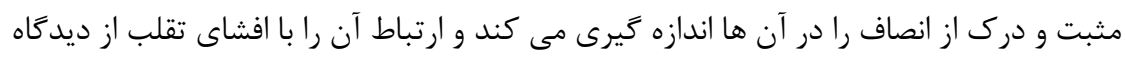

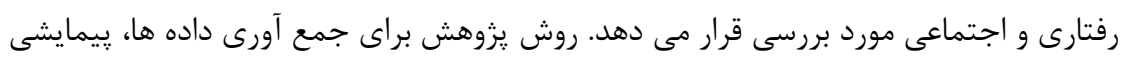

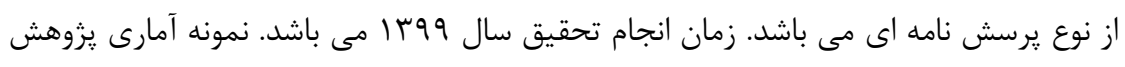

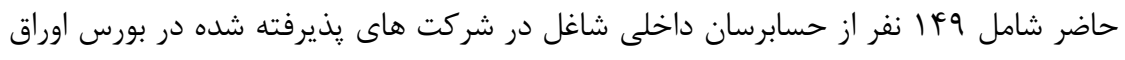

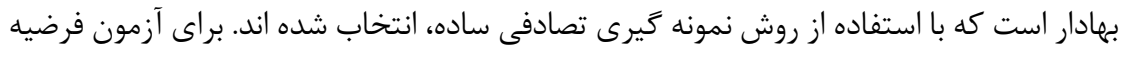

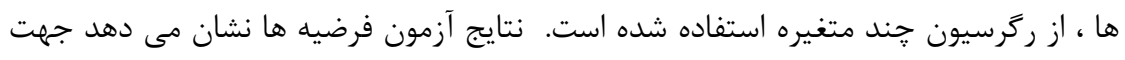

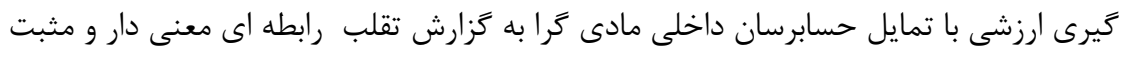

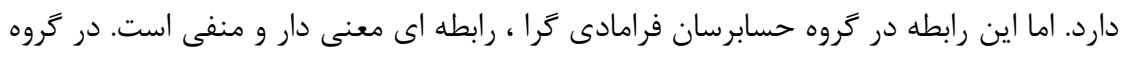

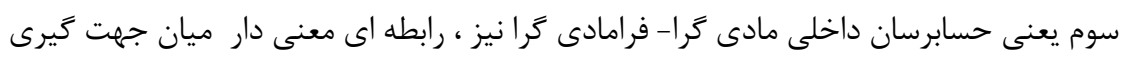

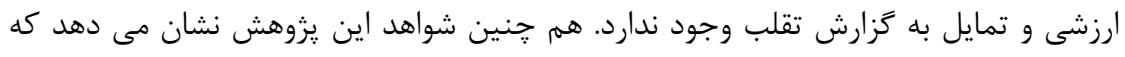

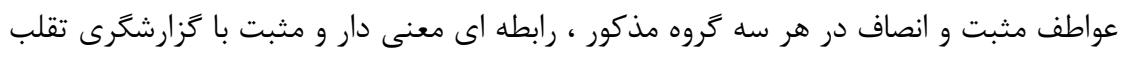

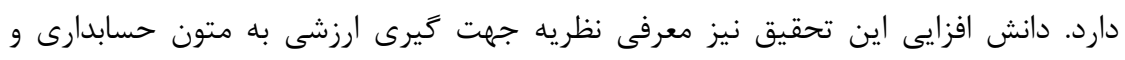

\footnotetext{
'دانشجوى دكترى تخصصى رشته حسابدارى، دانشكده مديريت و اقتصاد، واحد علوم و تحقيقات، دانشعاه آزاد اسلامى، تهران، ايران. (kadkhodaee.mojdeh@yahoo.com) r دانشيار و عضو هيات علمى،دانشكده مديريت و حسابدارى، واحد كرج، دانشعاه آزاد اسلامى،كرج، ايران (نوان dr.banimahd@gmail.com ، (نويسنده مسئول)
} 
دو فصلنامه حسابدارى ارزشى و رفتارى، سال ششم، شماره يازدهم، بهار و تابستان + +ع|

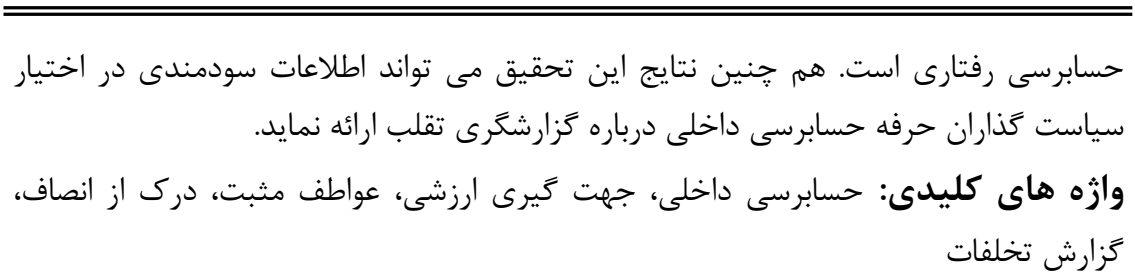


افشاى فعاليتهاى مشكوك و تخلفات اعضاى يك سازمان را كزارش تخلفات ' مى نامند. اين

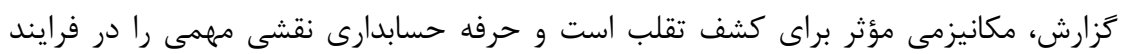

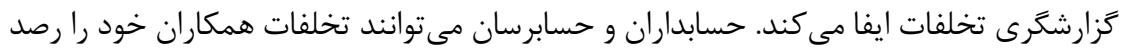

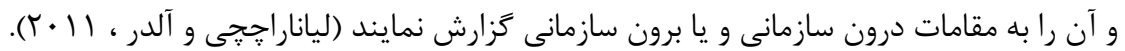

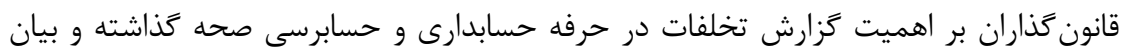

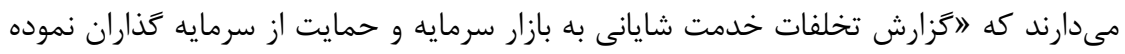

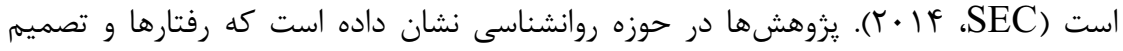
كيرىهاى اخلاقى افراد، به ويزگ يزوهشهاى رفتارى در حسابدارى و حسابرسى نشان دادندهاند كه قضاوت و تصميم كيرى افراد انداد

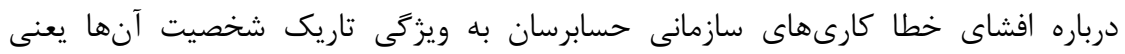

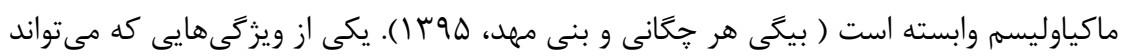

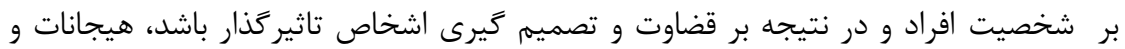

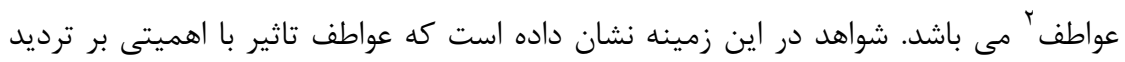

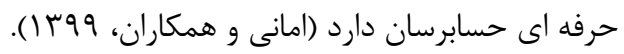

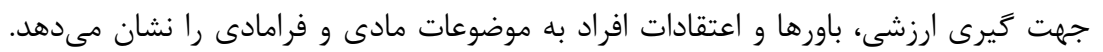

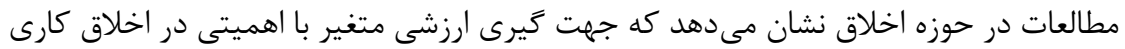

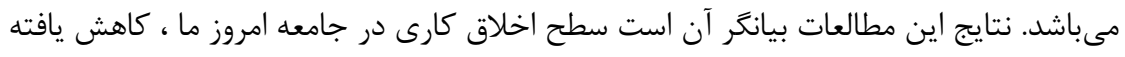

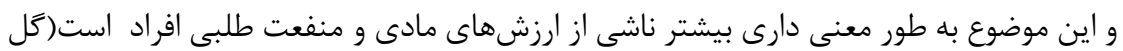

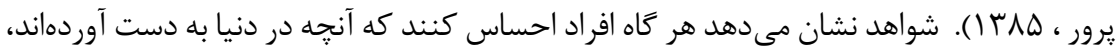

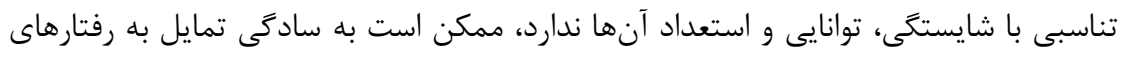

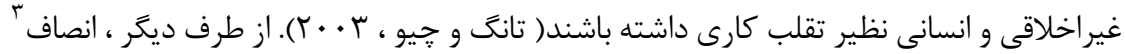

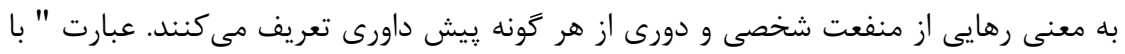

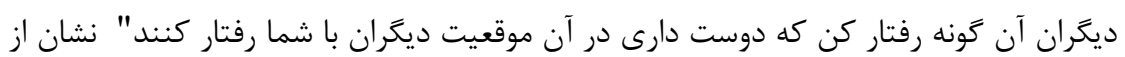

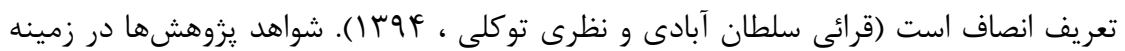

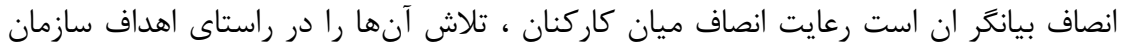

\footnotetext{
${ }^{1}$ Whistle-blowing

${ }^{2}$ Moods

${ }^{3}$ fairness
} 
افزايش داده و اخلاق كارى ارتقاء مى يابد. هم خنين بهبود عدالت، اعتماد و انصاف در سازمان

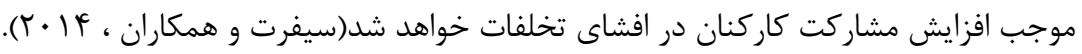

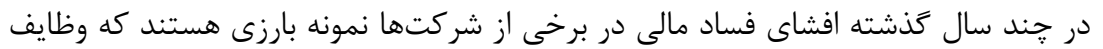

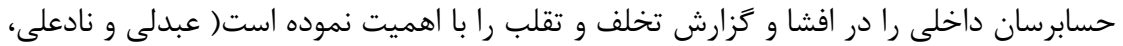

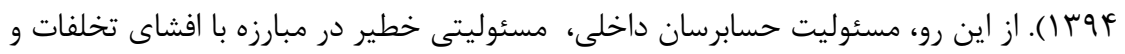

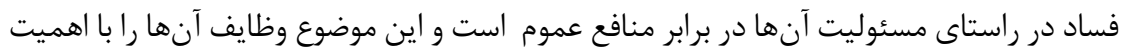

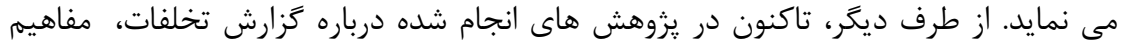

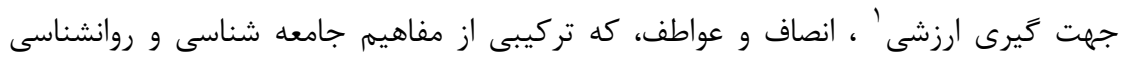

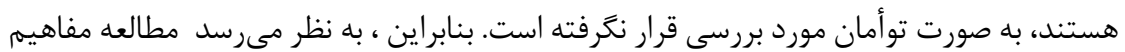

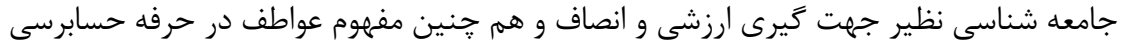

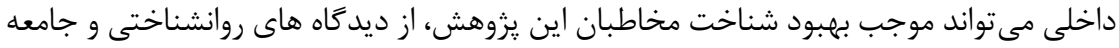

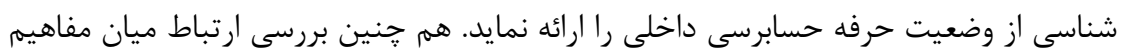
فوق با گزارش تخلفات در حرفه حسابرسى داخلى مىتواند اطلاعات سودمندى را در اختيار

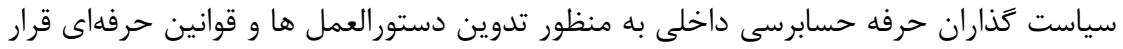

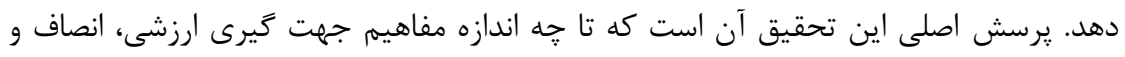

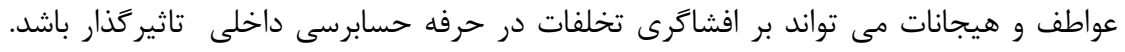

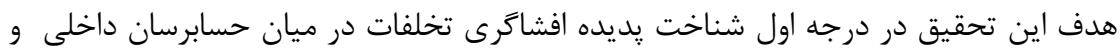

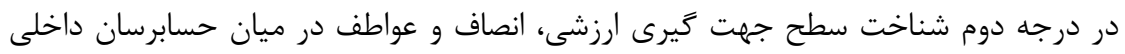

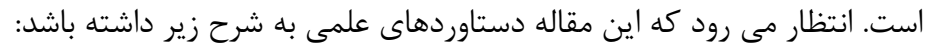

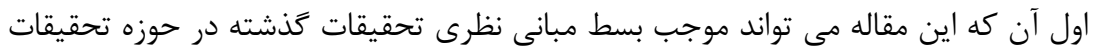

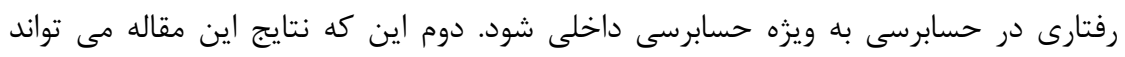

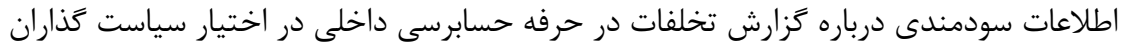

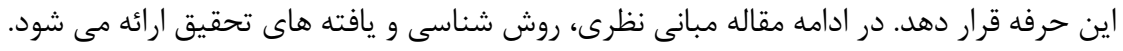

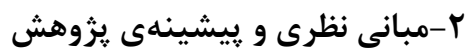

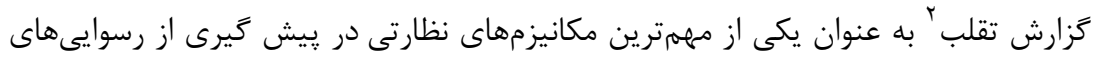
مالى درواحدهاى تجارى مطرح شده است. كزارش تقلب عبارت است از افشاى فئ فعاليتهاى

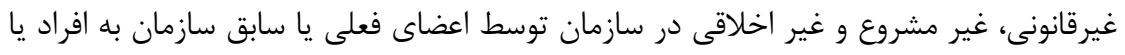
سازمانى هاى ذىربط. از حرفه حسابرسى داخلى و ديخر نهادهاى قانونى ذينفع خواسته شده

${ }^{1}$ Value Orientation

${ }^{2}$ Whistle-Blowing 
است كه كزارش تقلب را به عنوان يك بخش مههم و حساس از فرهنگ سازمانى ، در ساختار

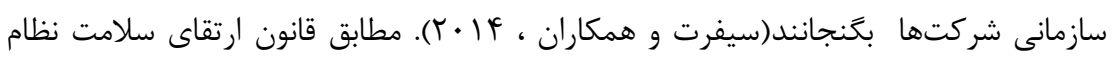

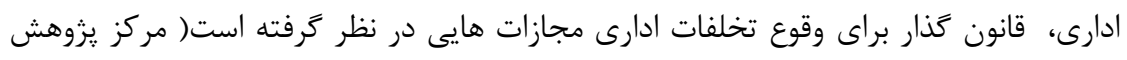

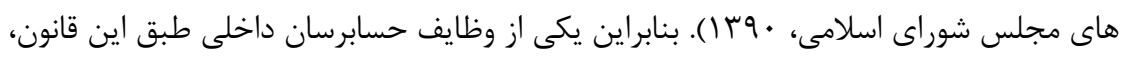

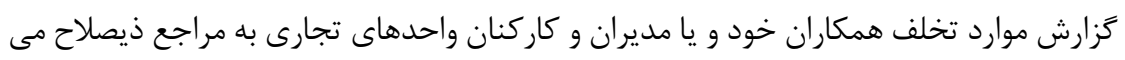

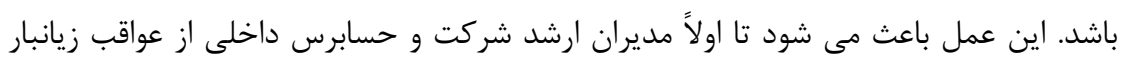

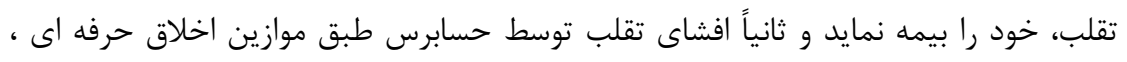

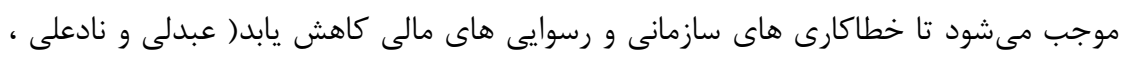

() (1)

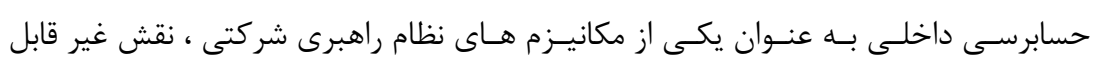

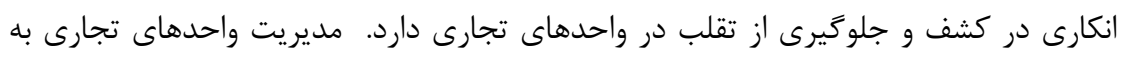

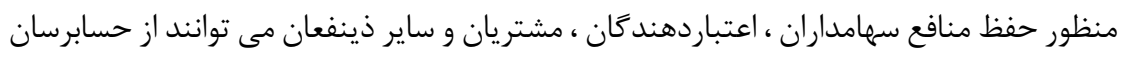

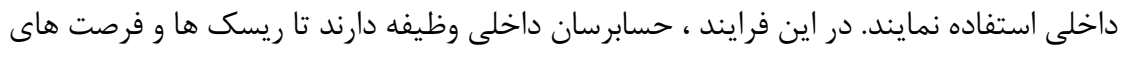
مرتبط با فعاليت واحد تجارى را شناسايى و ارزيابى نمايند.

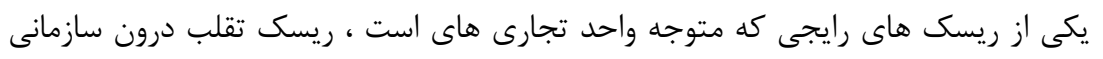

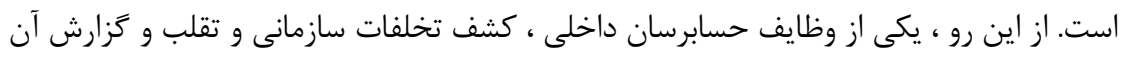

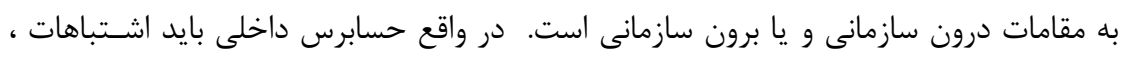

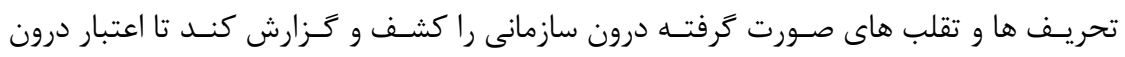

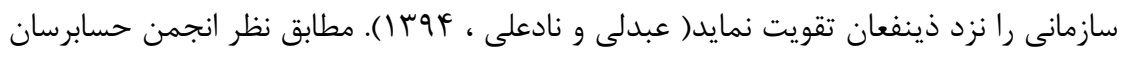

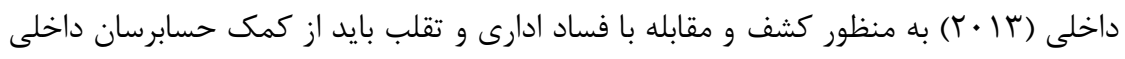

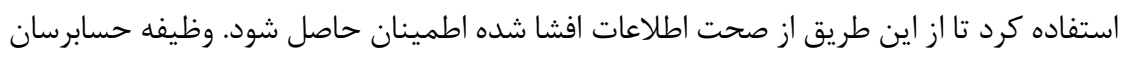

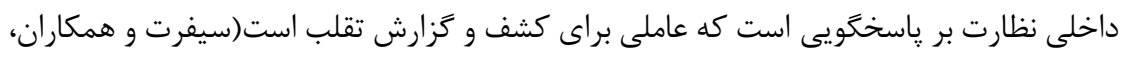

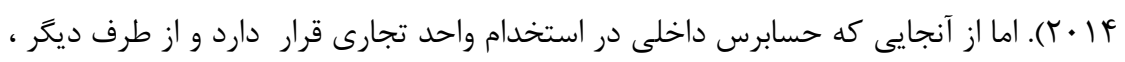

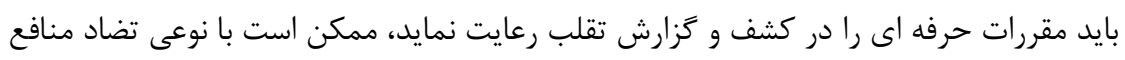

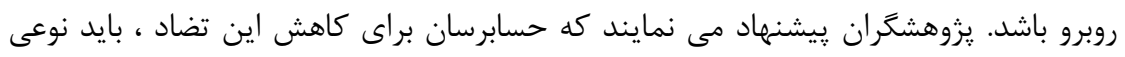

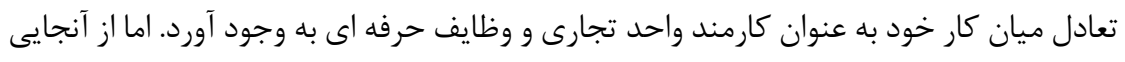

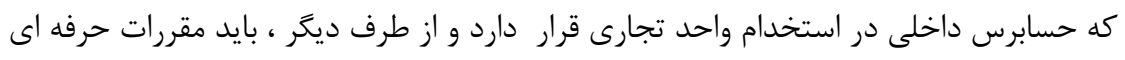

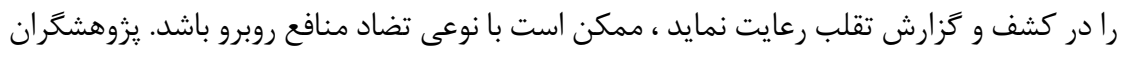

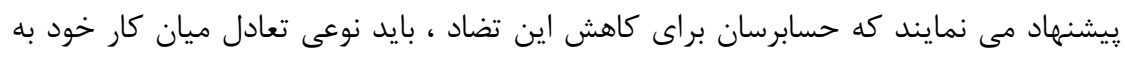

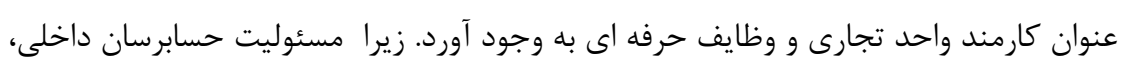


مسئوليتى خطير در مبارزه با افشاى تخلفات و فساد در راستاى مسئوليت آنها در برابر منافع

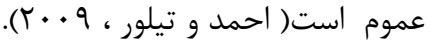

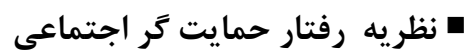

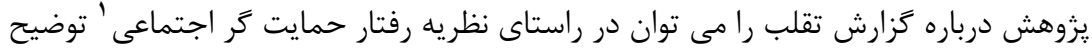

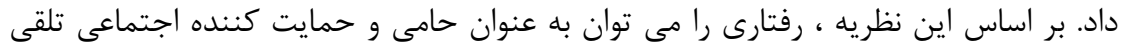

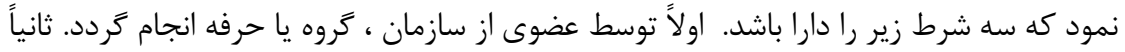

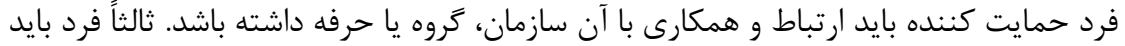

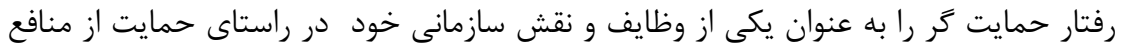

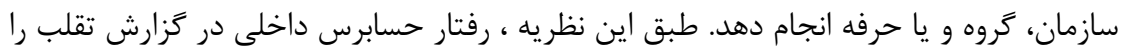

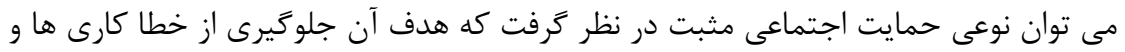

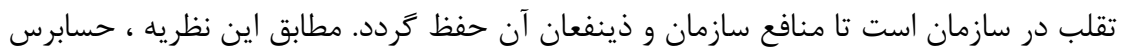

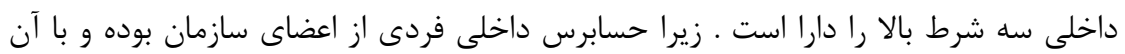

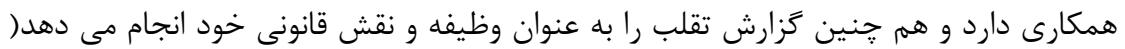

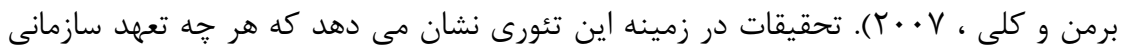

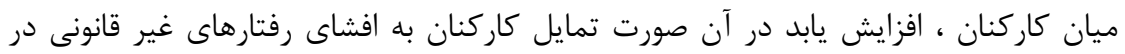

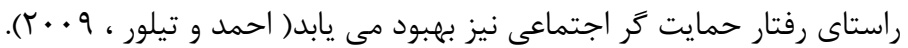

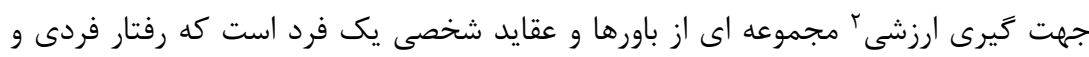

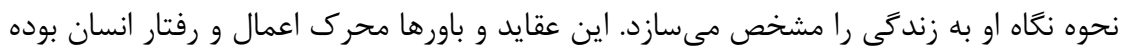

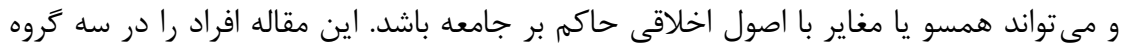

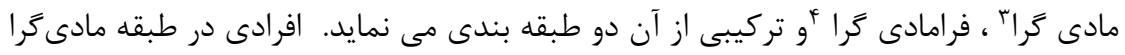

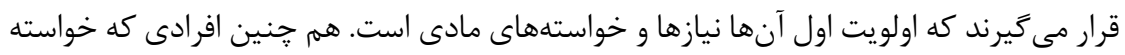

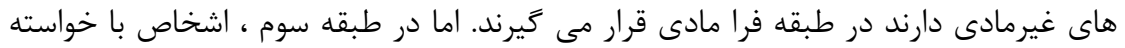

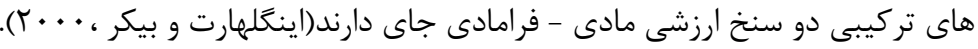

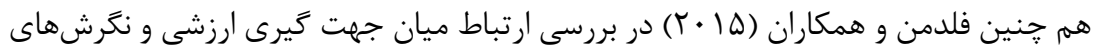

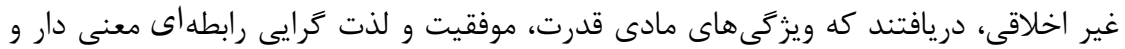

${ }^{1}$ Prosocial Behavioural Theory

${ }^{2}$ Value Orientation

${ }^{3}$ materialistic

${ }^{4}$ post materialist 
مثبت با رفتار غير اخلاقى دارد. اما ويزگى هاى فرامادى نظير خيرخواهى و عام كرايى و هم جنين

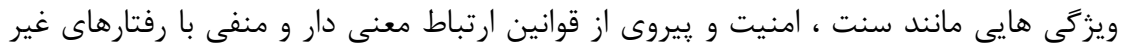

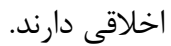

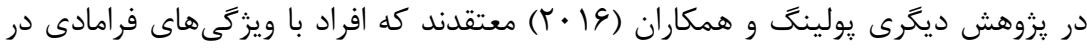

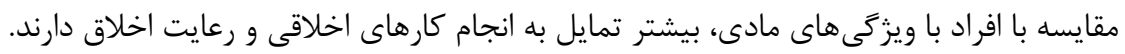

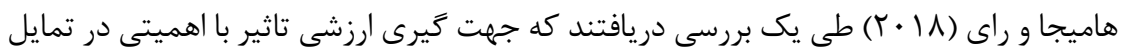

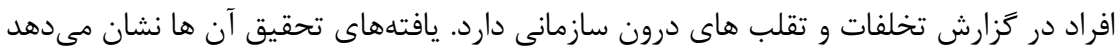

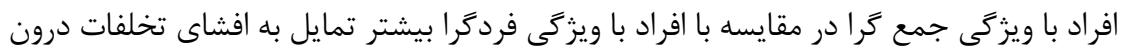

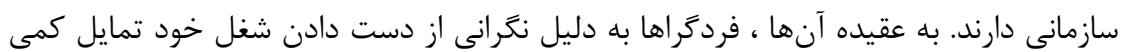

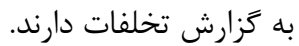

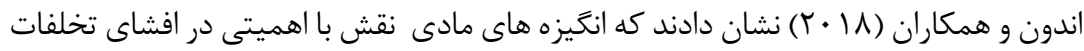

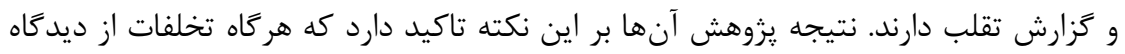

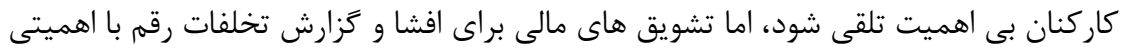

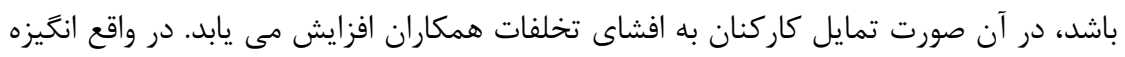

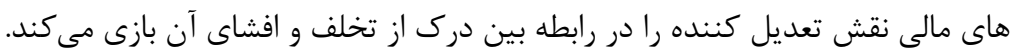

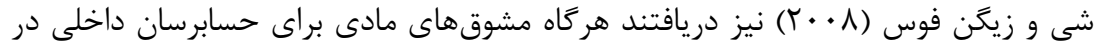

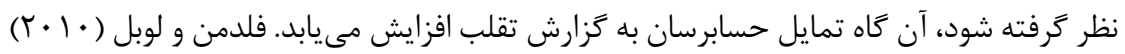

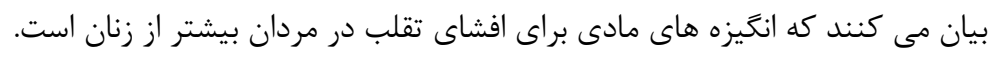

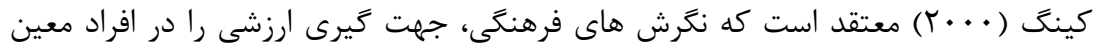

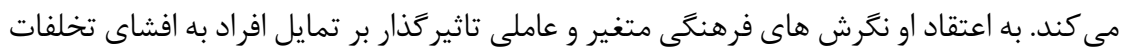

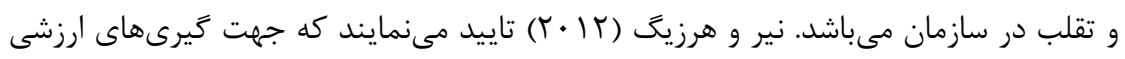

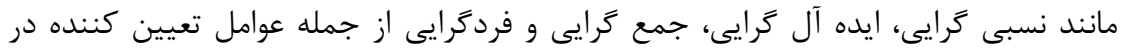

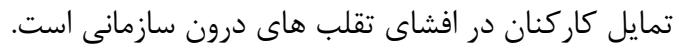

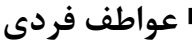

عاطفه، وازهاى است كه براى توضيح طيف وسيعى از احساسات مبتنى بر خصايص و حالات

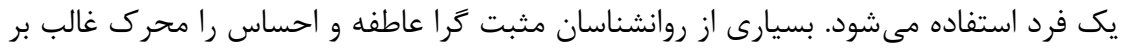

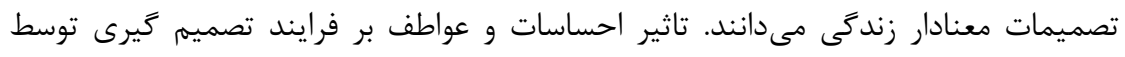

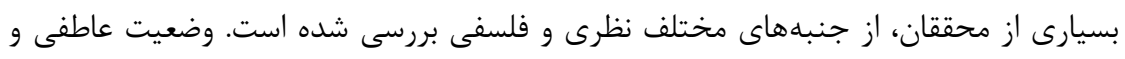

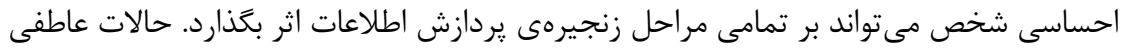

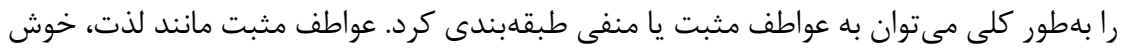


بينى، علاقه مندى و... و عواطف منفى همجون خشم، افسردىى، ترس و ناميدى و ... است.

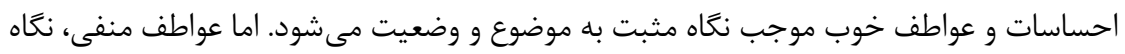

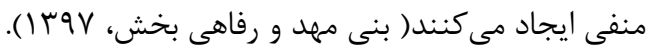

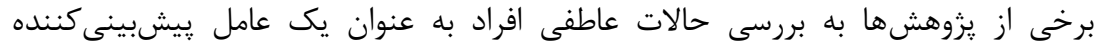

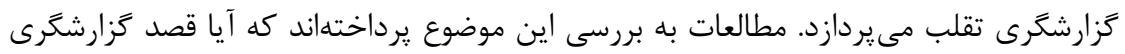

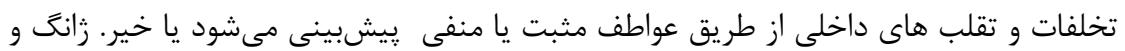

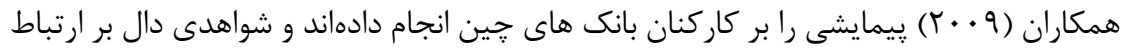

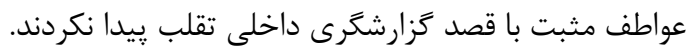

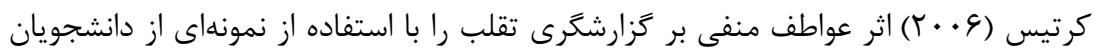

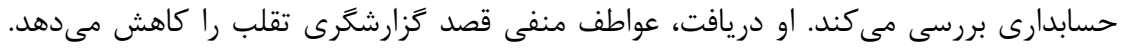

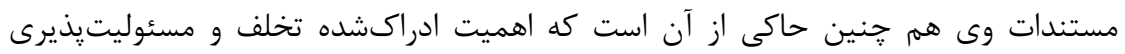
ادراكشده براى كزارش تخلف رابطهى بين عواطف منفى و قصد كزارشكرى تقلب را تسمهيل ركرز- سوسيوك و همكاران( • • (T) انواع خاص حالات عاطفى را بررسى كردند. آن ها دو نوع

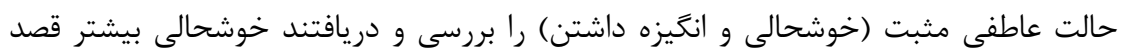

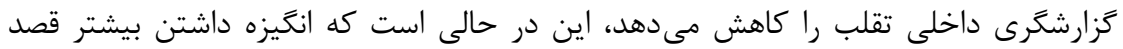

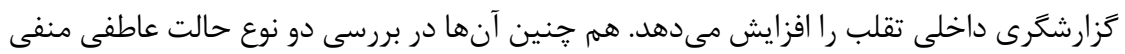

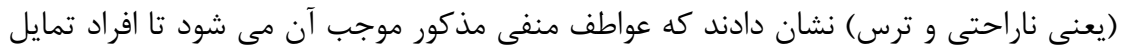
كمترى به كزارش تقلب داشته باشندا

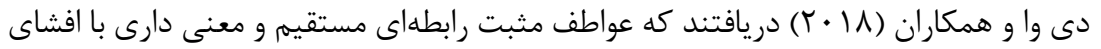

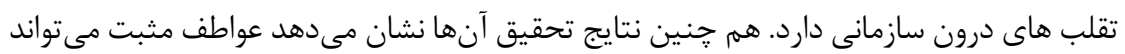

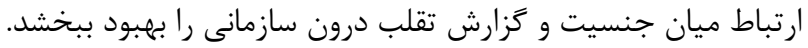

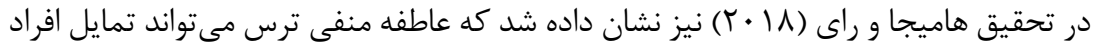

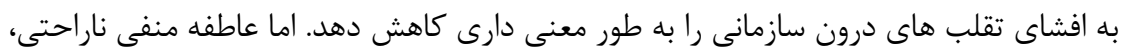
رابطه اى معنى دار با افشاى تقلب درون سازمانى ندارد.

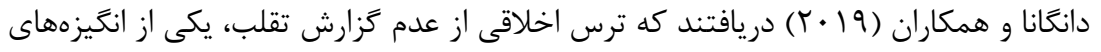

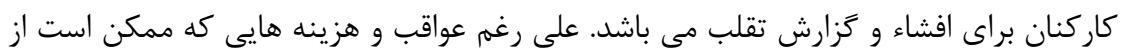

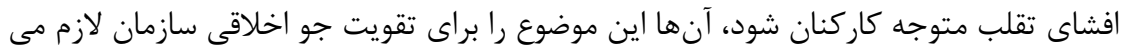




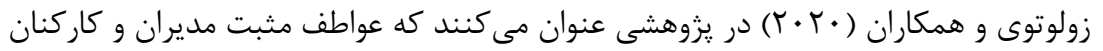

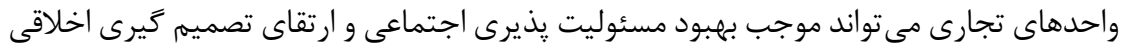

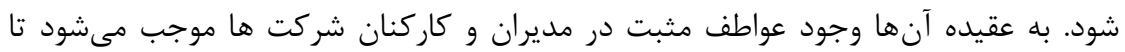

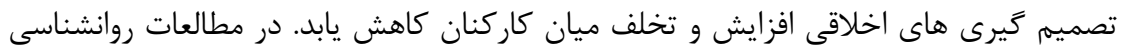

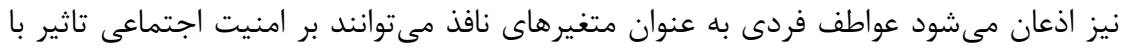

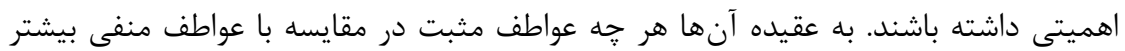

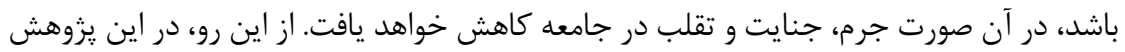

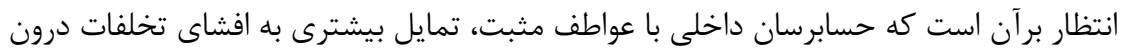

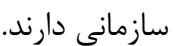

\section{a}

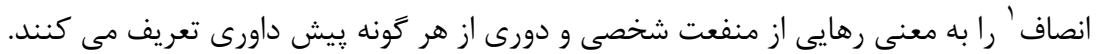

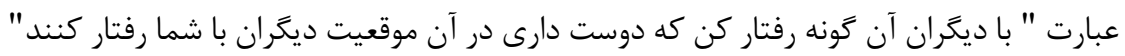

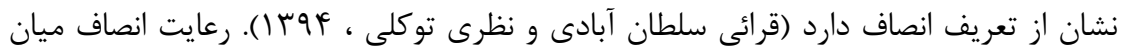

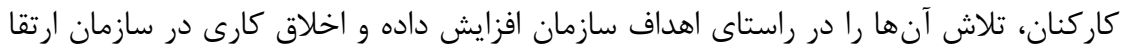

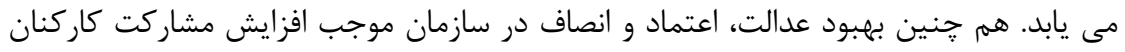

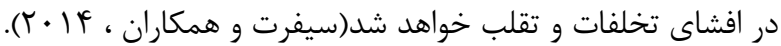

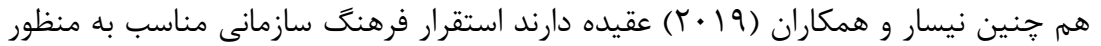

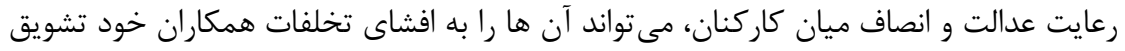

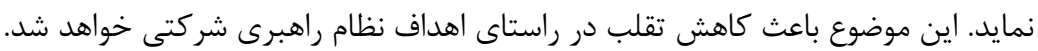

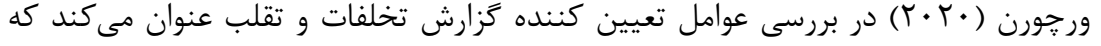

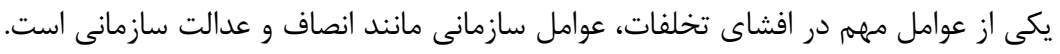

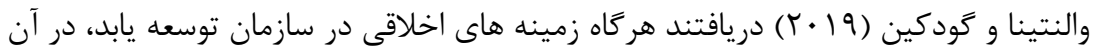

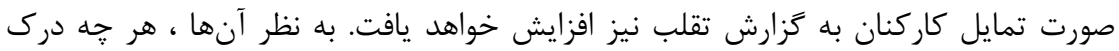

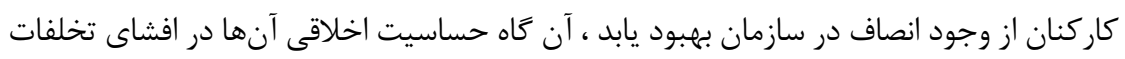

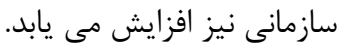

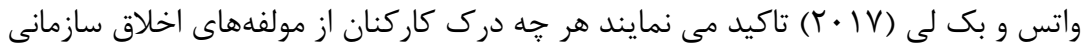

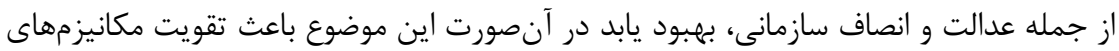
افشاى تخلفات و تقلب سازمانى توسط كاركنان سازمان مى شود.

${ }^{1}$ Fairness 


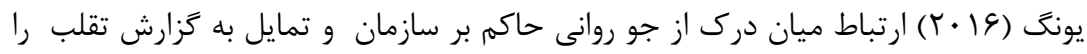

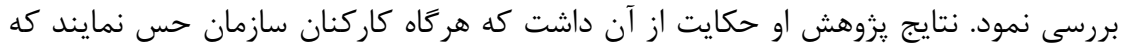

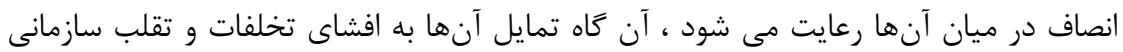
بيشتر مى شود.

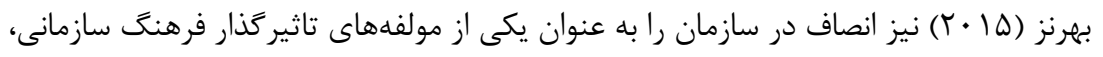

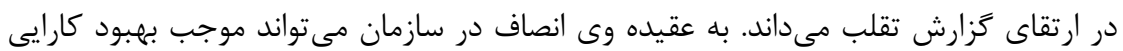
مكانيزم هاى كشف تقلب در سازمان شود.

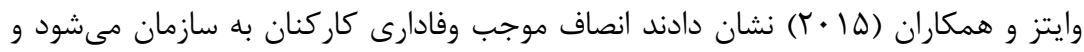

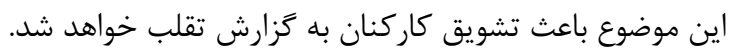

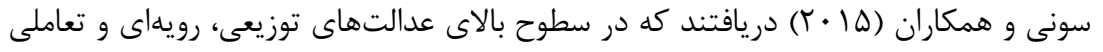

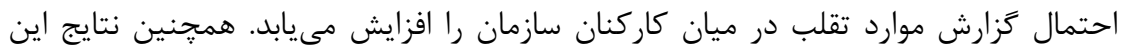

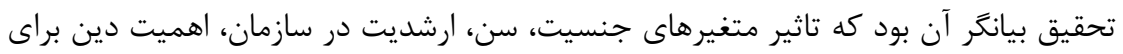
شخص و نمره عملكرد وى تاثير معنادارى بر قصد گزارش داخلى موارد تقلب ندارد.

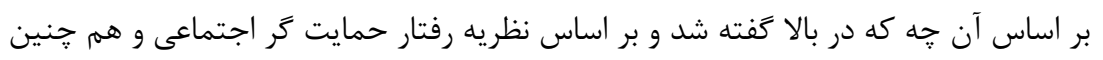

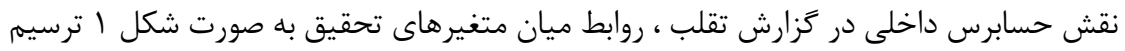
مى شود. شكل 1- مدل كلى تحقيق

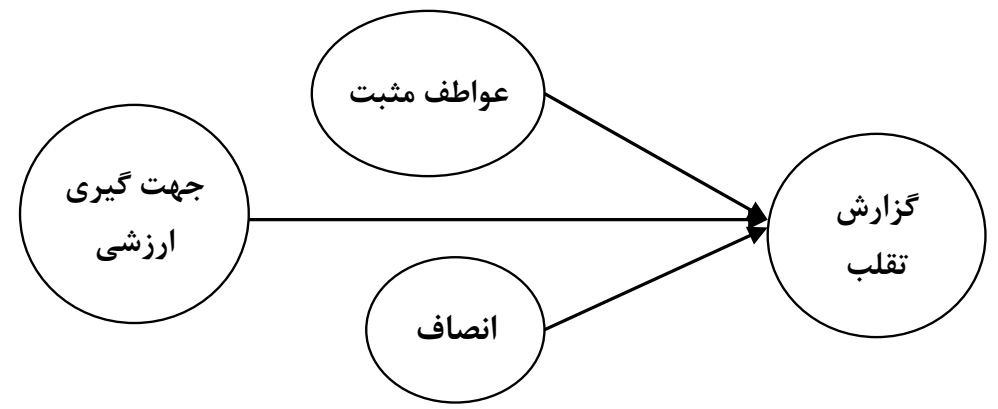

\section{r-فرضيه هاى تحقيق}

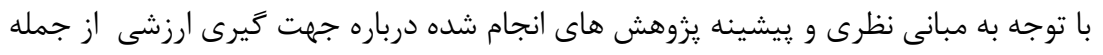

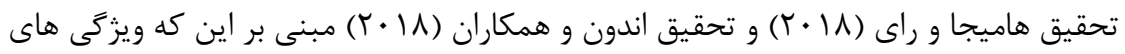

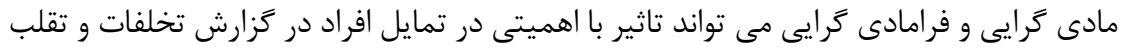

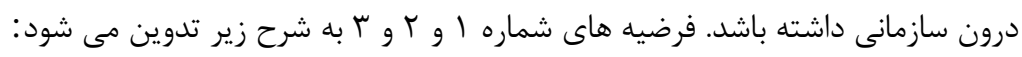


فرضيه ا: جهت كيرى ارزشى در حسابرسان داخلى با ويزگى مادى گرا با تمايل آنها به كزارش تقلب رابطه معنى دار دارد.

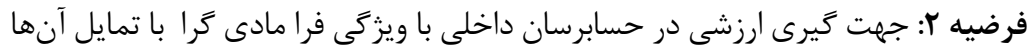
به كزارش تقلب رابطه معنى دار دارد.

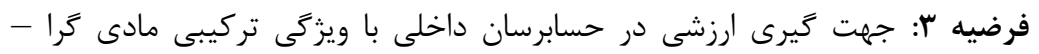

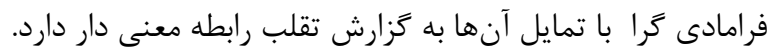

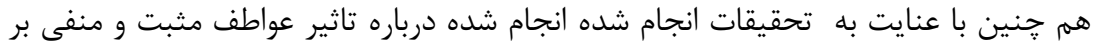

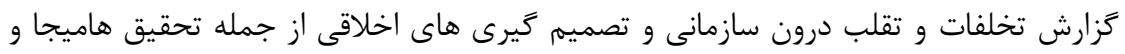

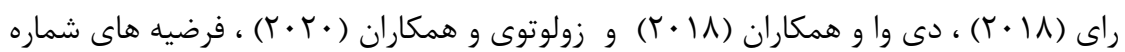
أوهو 4 به شرح زير نوشته مى شود:

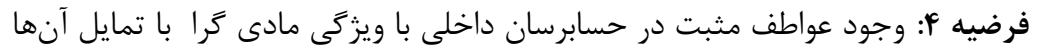

$$
\text { به كزارش تقلب رابطه معنى دار دارد. }
$$

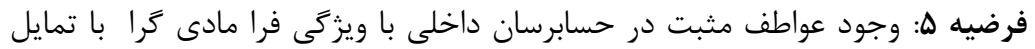

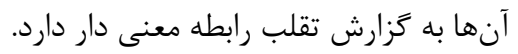

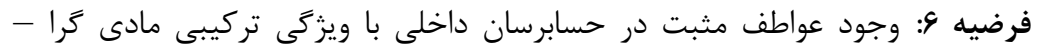

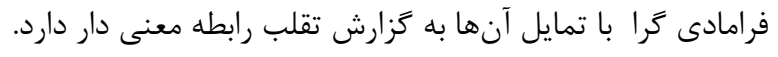

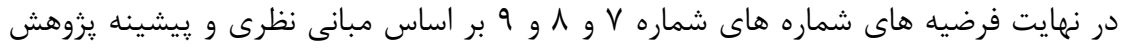

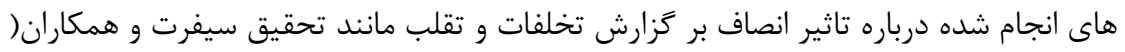

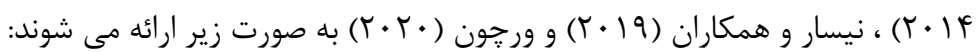

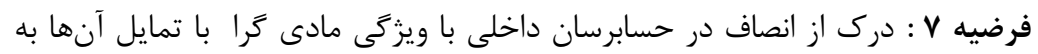
كزارش تقلب رابطه معنى دار دارد.

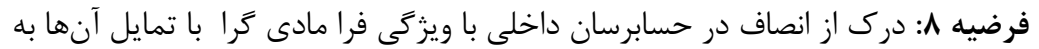
كزارش تقلب رابطه معنى دار دارد.

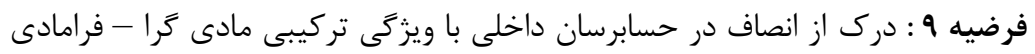
كرا با تمايل آنها به كزارش تقلب رابط رابطه معنى دار دارد.

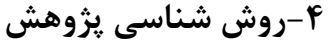

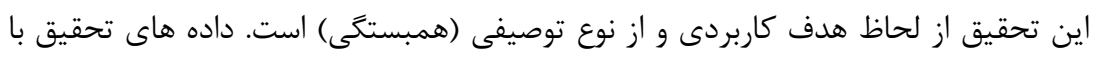

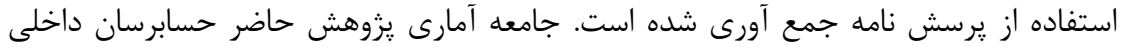
شاغل در شركت هاى يذيرفته شده در بورس اوراق بهادار مى باشد. از آنجايى كه تعداد حسابرسان
} 
شاغل در شركت هاى يذيرفته شده در بورس اوراق بهادار مشخص نمى باشد ، لذا در اين يزوهش

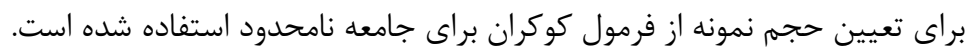

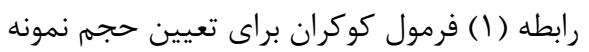

$n=\frac{Z_{\frac{\alpha}{2}}^{2} p q}{d^{2}}$

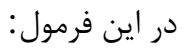

تعداد نمونه

$\frac{\alpha}{2}$

مقدار نرمال استاندارد يعنى 1/94

$\mathrm{P}=\mathrm{q}=0 / 5$

$\mathrm{d}=0 / 1$

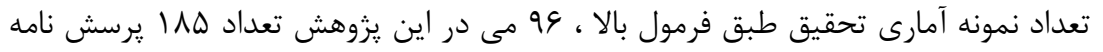

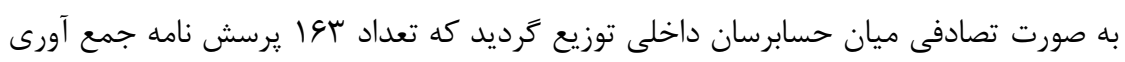

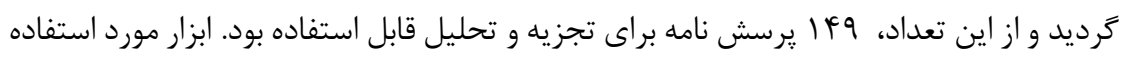

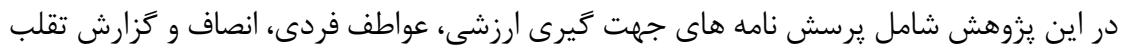

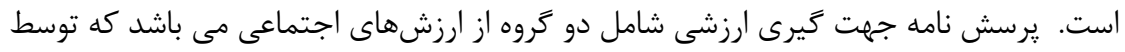

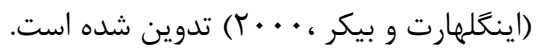

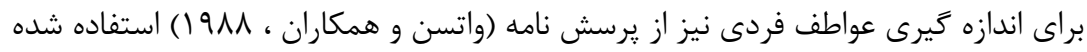

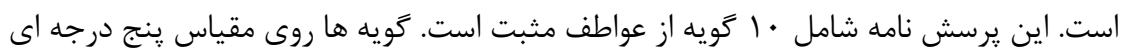

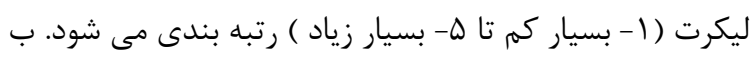

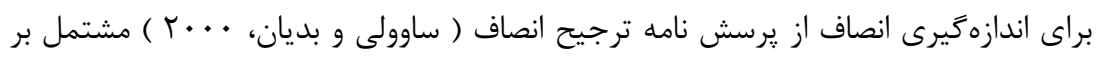
19 كويه استفاده شده است.

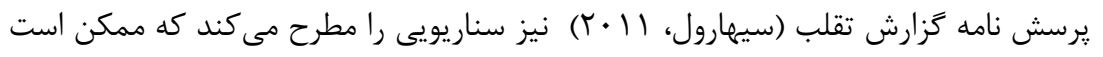

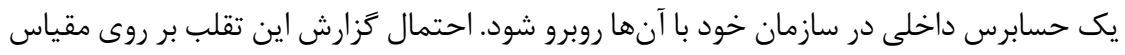

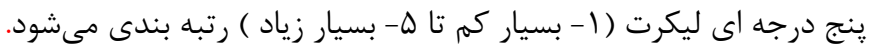

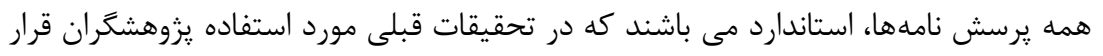

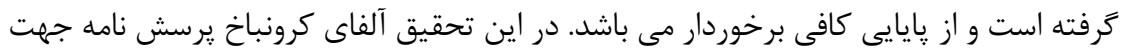

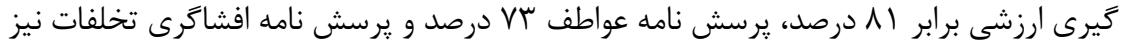

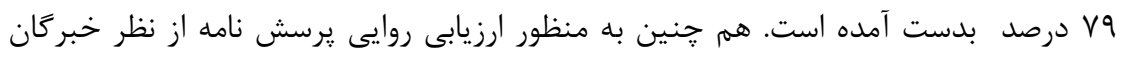

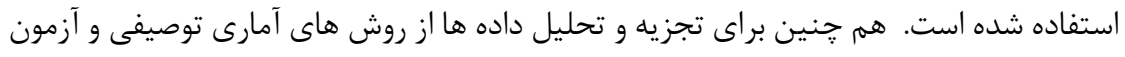


فرضيه ها از ركرسيون קند متغيره استفاده شده است. متغير وابسته در اين يزوهش، تمايل به

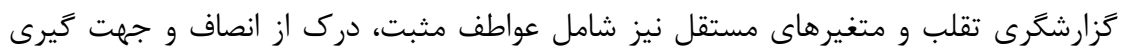

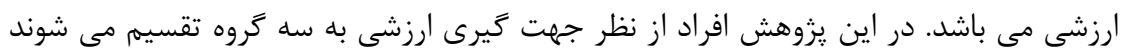

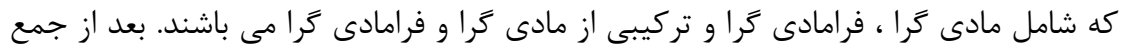

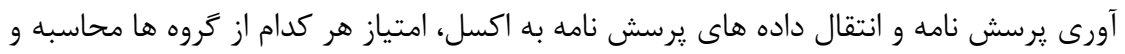

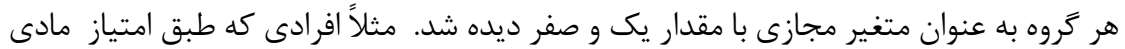

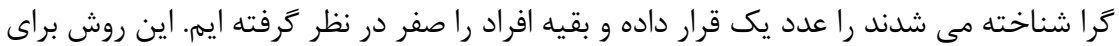

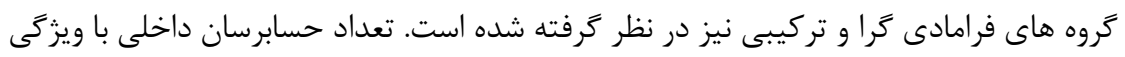

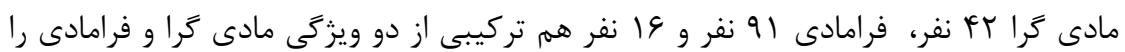
برخوردار بودند. هم جنين متغيرهاى جنسيت و سن نيز به عنوان متغيرهاى كنترل در نظر كر كرفته

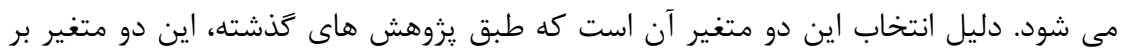

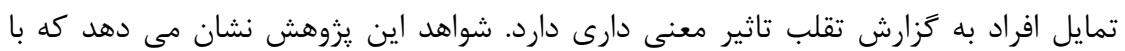

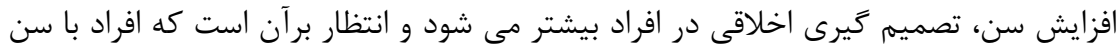

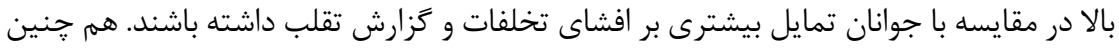

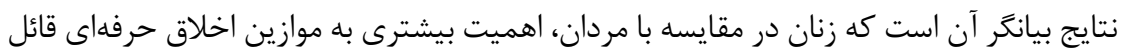

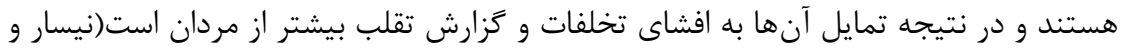

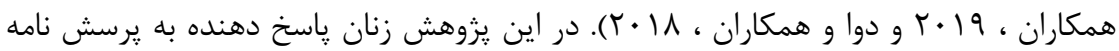
سأ و مردان نيز 9.

$\mathrm{Y}=\mathrm{a}_{0}+\mathrm{a}_{1} \mathrm{X}_{1}+\mathrm{a}_{2} \mathrm{X}_{2}+\mathrm{a}_{3} \mathrm{X}+\mathrm{a}_{4} \mathrm{X}_{4}+\mu$ مدل يزوهش نير به صورت زير نوشته مى شود:

Y= تمايل به كزارش تخلفات

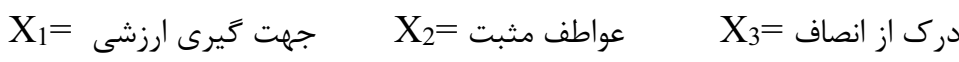

خطاى مدل =

ه-يافته هاى تحقيق

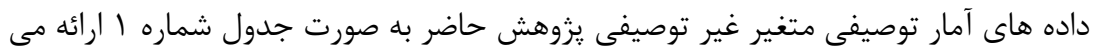

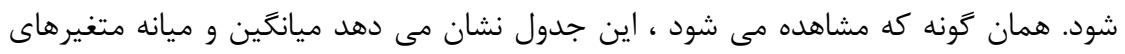

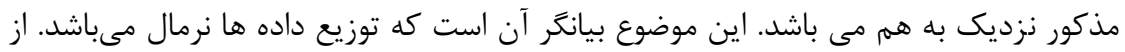

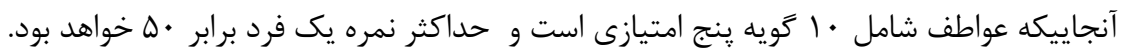




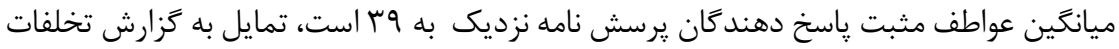

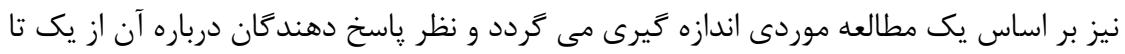

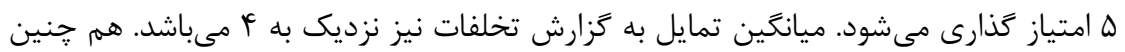

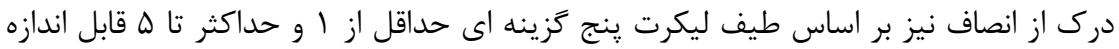

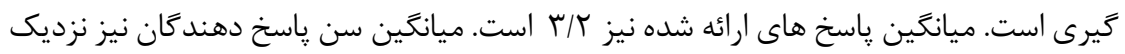

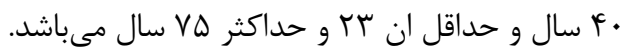

\begin{tabular}{|c|c|c|c|c|}
\hline \multicolumn{5}{|c|}{ جدول شماره | : امار توصيفى } \\
\hline سن & درك از انصاف & تمايل به كزارش تخلفات & عواطف مثبت & شرح \\
\hline rq/q & $r / T \cdot \Delta$ & $r / 9 \Lambda$ & rN/vq & ميانكين \\
\hline rv & r/\AV & r & rq & ميانه \\
\hline 1.199 &.$/ 4 T V$ & .1999 & F/FHT & انحراف معيار \\
\hline r & $|/ \wedge|$ & 1 & re & حداقل \\
\hline Va & $\Delta$ & $a$ & $\Delta \cdot$ & حداكثر \\
\hline
\end{tabular}

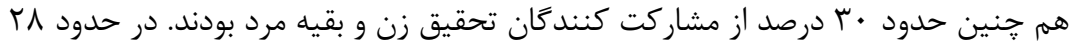

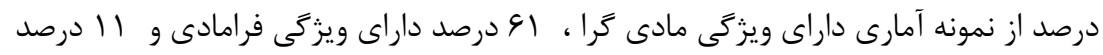

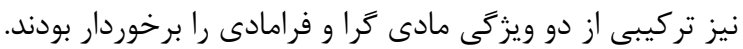

\section{نتايج آزمون فرضيه ها}

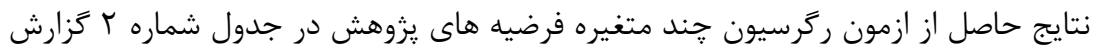

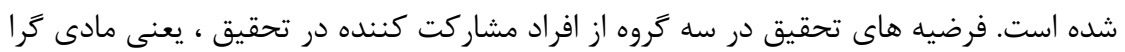

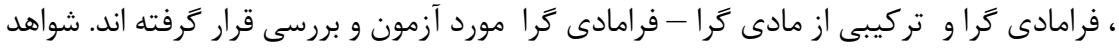

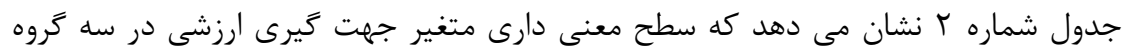

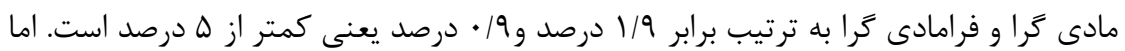

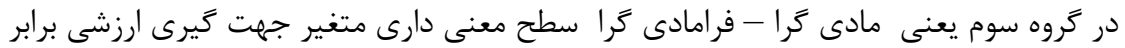

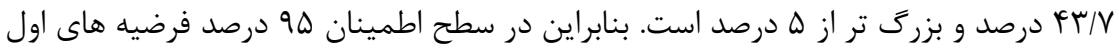

$$
\text { و دوم تاييد و فرضيه سوم رد مى شئ شود. }
$$

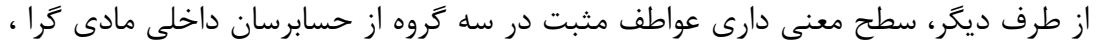

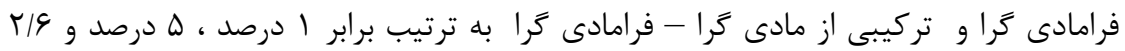

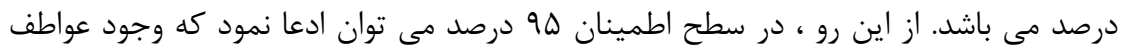

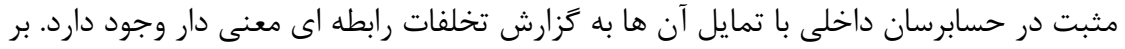


اين اساس فرضيه هاى شماره جهارم و ينجم و ششم تاييد مى شوند. هم جنين براى ازمون

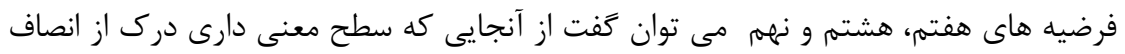

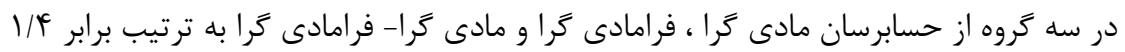
درصد ، 9/ • درصد و ه/ • درصد و همه كمتر از هـ درصد است، بنابراين درك از انصاف با تزارش

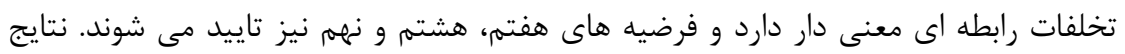

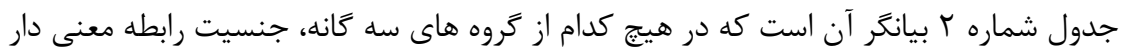

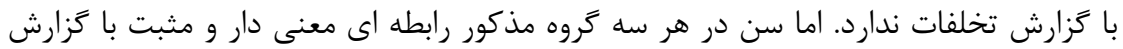

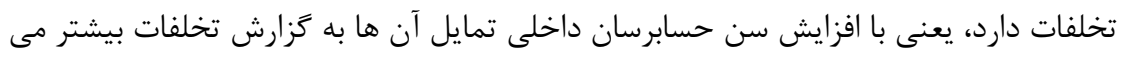

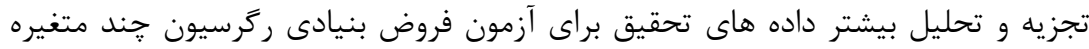

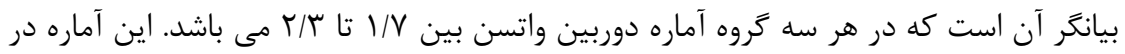

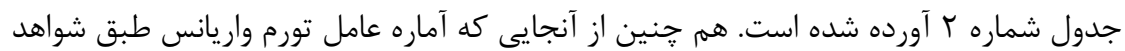

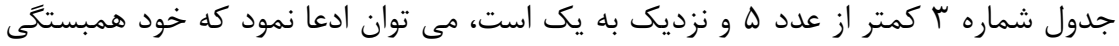

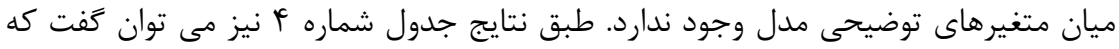

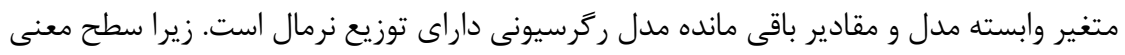

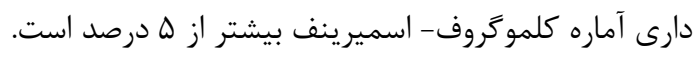

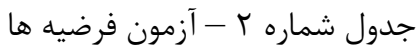

\begin{tabular}{|c|c|c|c|c|c|c|c|c|c|}
\hline \multicolumn{3}{|c|}{ مادى گرا - فرا مادى ترا } & \multicolumn{3}{|c|}{ فرامادى گرا } & \multicolumn{3}{|c|}{ مادى ترا } & \\
\hline | دارى & آماره t & ضرايب & مارى & t T آماره t & ضرايب & مارى & t آماره t & ضرايب & \\
\hline$\cdot / \wedge 9$. &.$- / 1 \% 9$ &.$- / 1 r 人$ & - |QDS & - /FAT & - $/ F F F$ & - $/$ NAT & $\cdot / 1 \wedge \Delta$ & $\cdot|1 \wedge|$ & مقدار ثابت \\
\hline$\cdot / \pi r \cdot$ & $-1 / \Gamma T$ & $-\cdot / \Gamma \mid \Lambda$ & ו וTM & -.1999 &.$- / 1 V T$ & (THE & $-1 / 19$. & $-\cdot / r \cdot 9$ & جنسيت \\
\hline$\cdot 1 \cdots$ & r/VFD & $\cdot 1 \cdot r q$ & $\cdot \cdots$ & r/q५द & $.1 \cdot r_{9}$ & $\cdot 1 \cdot$ & $r / l \Delta T$ & $\cdot|\cdot r|$ & 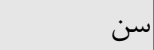 \\
\hline$\cdot 1 \cdot \cdot \Delta$ & r/Arq & $\cdot / 499$ & $.1 \cdot .9$ & $r / 9 \mu$. & - FAT & .1 .14 & $r / \& V \varepsilon$ & . $\mid$ AMI & درك ازانصاف \\
\hline . & T/MFY & $\cdot \mid \cdot r q$ & $\cdot|\cdot \Delta|$ & $1 / 9 V T$ & $.1 . \mu F$ & $.1 \cdot 1$ & T/ATY & $\cdot \mid \cdot \Delta 1$ & عواطف مثبت \\
\hline$\cdot / 4 r v$ & - /VVq & .1194 & $\cdot 1 \cdot .9$ & $-r / 994$ & $-\cdot / 4 \cdot V$ & $\cdot 1 \cdot 19$ & $r / r V q$ & $\cdot / 4 \cdot 4$ & جهت گريرى \\
\hline$\cdot \cdots \cdot$ & & $\varphi / \Delta \Delta \varphi$ & $\cdot 1 \cdot \cdot$ & & $Q / \cdot \Delta F$ & $\cdot 1 \cdot \cdot$ & & D/VTr & F آماره F F F \\
\hline \multicolumn{3}{|c|}{ ضريب تعيين = V • | • } & \multicolumn{3}{|c|}{ ضريب تعيين = \& | || • } & \multicolumn{3}{|c|}{ ضريب تعيين = |lYA } & \\
\hline
\end{tabular}


دو فصلنامه حسابدارى ارزشى و رفتارى، سال ششم، شماره يازدهم، بهار و تابستان ++ع|

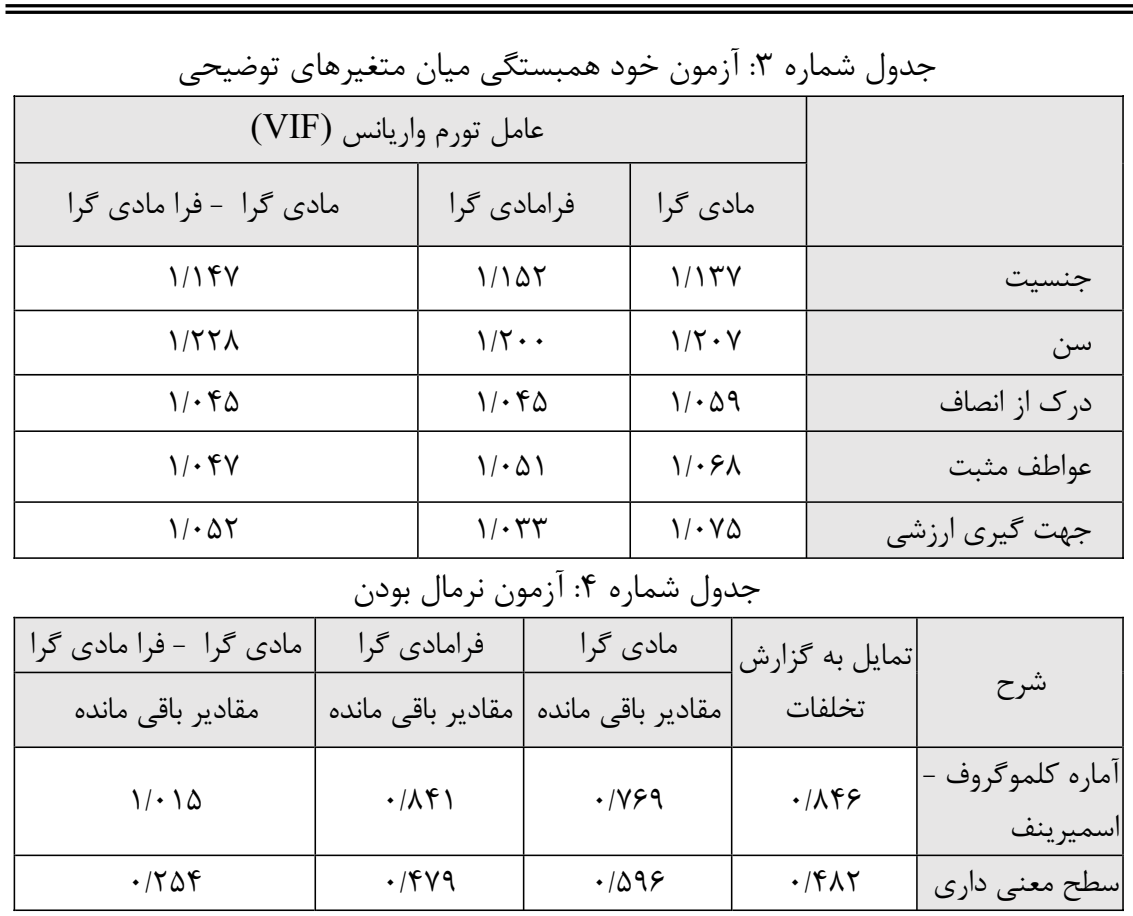

\section{9-نتيجه گَيرى و بحث}

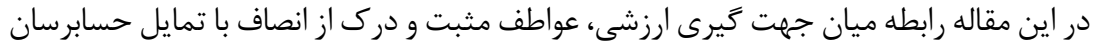

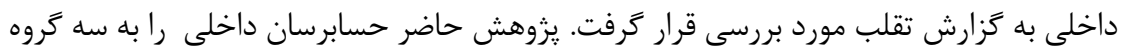

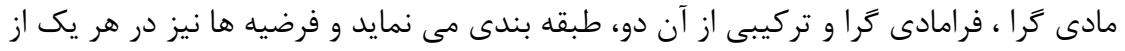

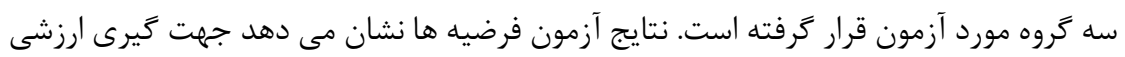

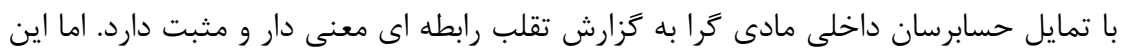

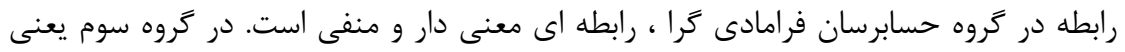

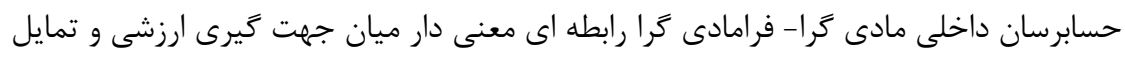

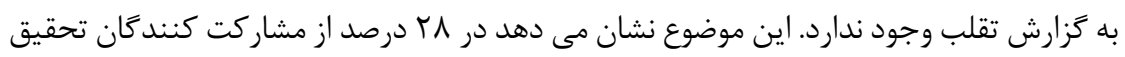

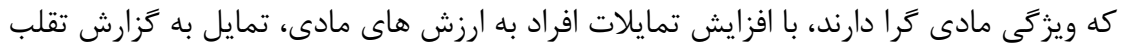

$$
\text { نيز افزايش مى يابد. }
$$

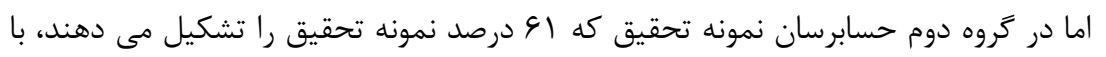

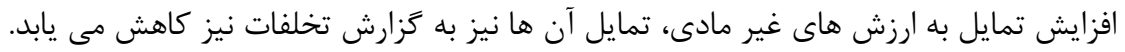

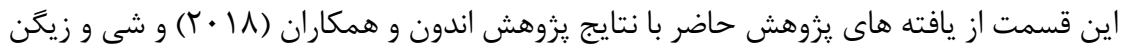




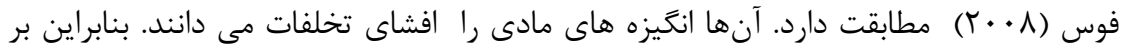

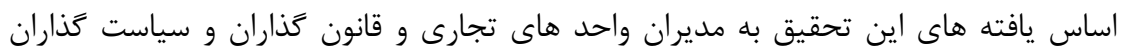

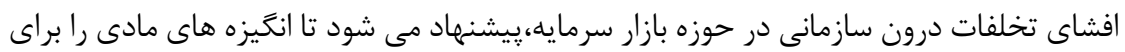
افشاى تخلفات توسط حسابرسان مد نظر قرار دهند. هم جنين هنغام استخدام حسابرسان داخلى

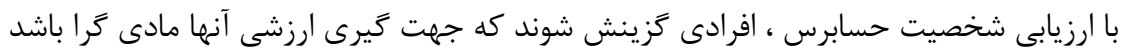

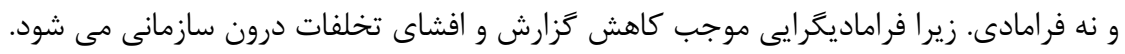

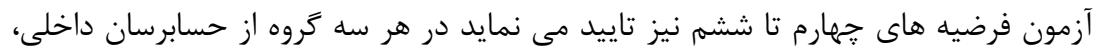

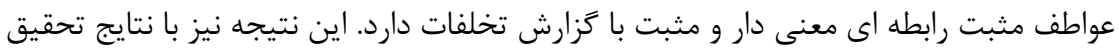

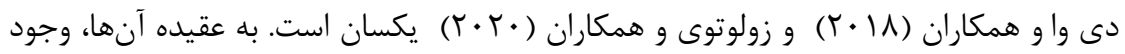
عواطف مثبت در افراد مىتواند موجب بهبود مسئوليت يذيرى اجتماعى و ارتقاى تصميم كيرى

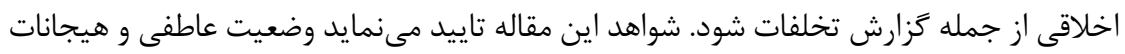

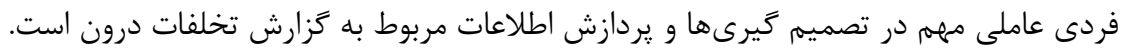

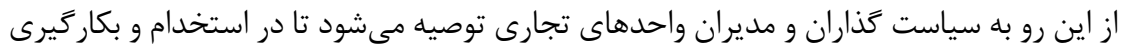

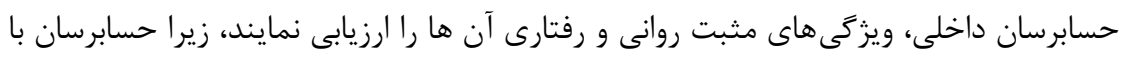

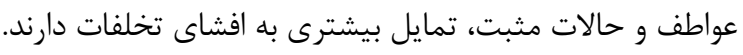

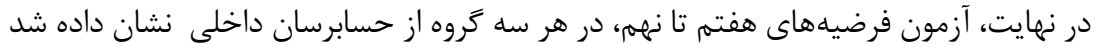

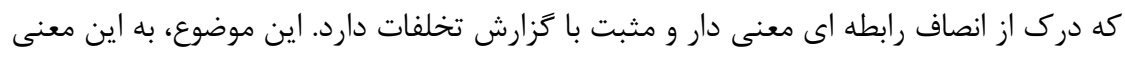

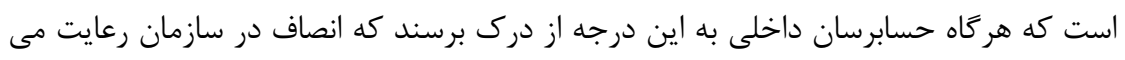

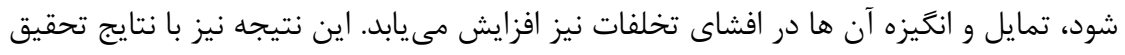

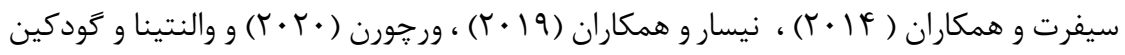

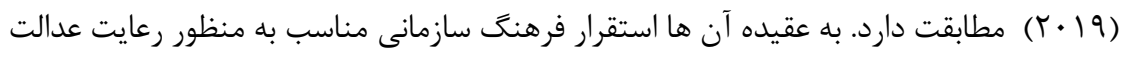

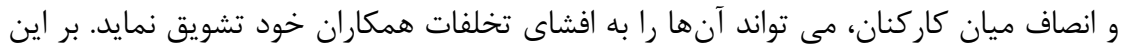

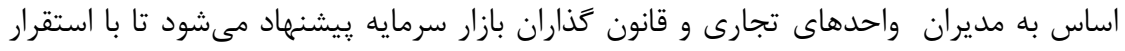

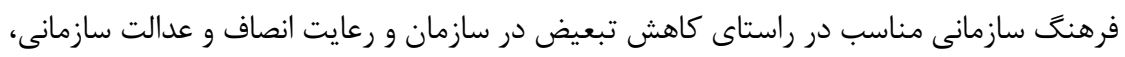

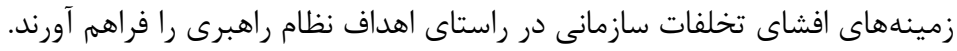

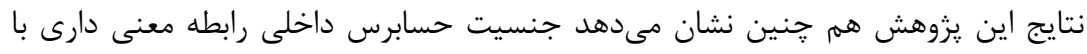

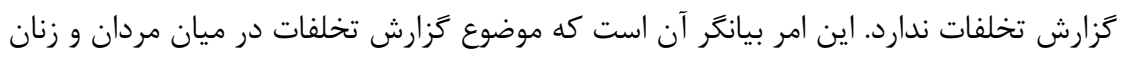

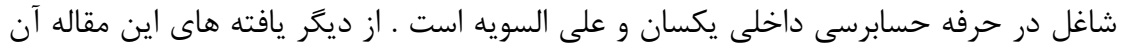

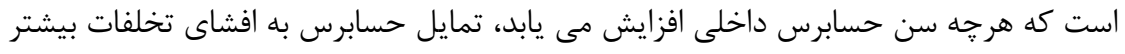

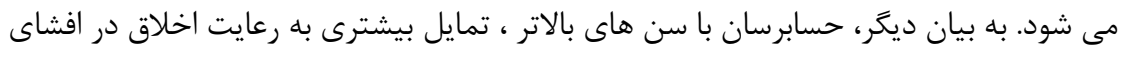


تخلفات دارند. از اين رو ، حسابرسان با سابقه كار بيشتر و با تجربه تر مى توانند حسابرسان كم

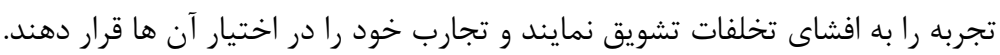

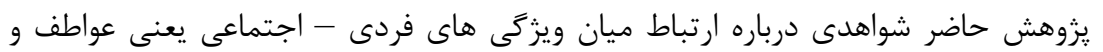

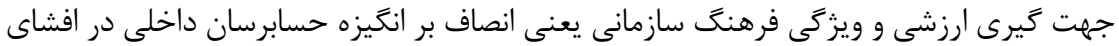

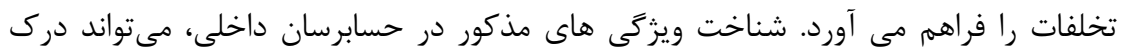

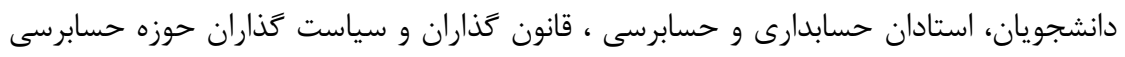

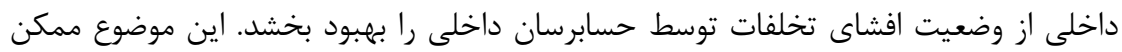

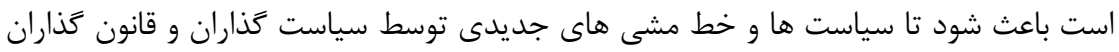

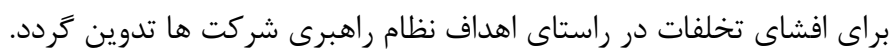
تعميم نتايج تحقيق حاضر به جامعه آمارى ديخر را مى توان از محدوديت هاى اصلى اصلى اين تحقيق

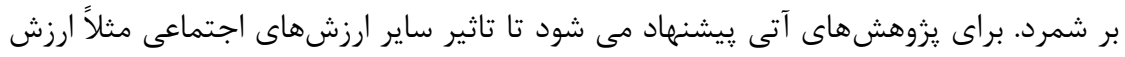

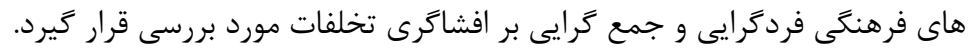

V - Vقدير، تشكر و ملاحظات اخلاقى - V

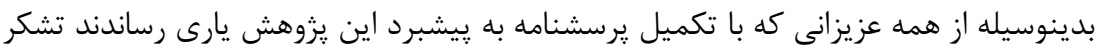
و قدردانى مى نماييم

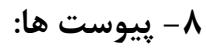
الف- يرسشنامه كَزارش تخلفات حسابرس داخلى شركت در زمان انجام حسابرسىهاى مربوط به خريد كالا توسط شركت مت متوجه

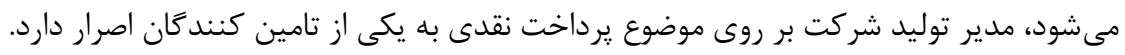

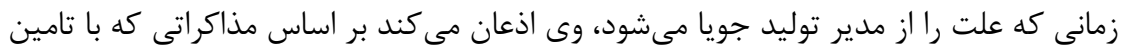

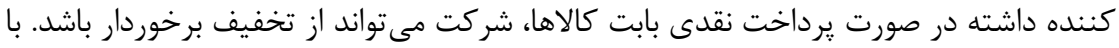

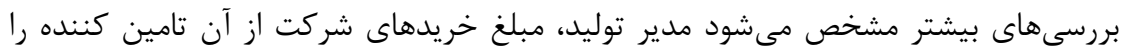

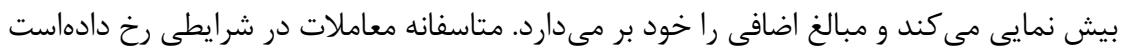

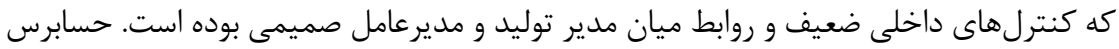

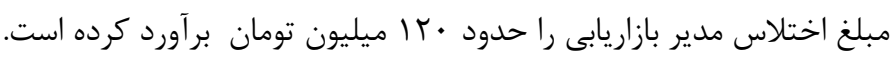

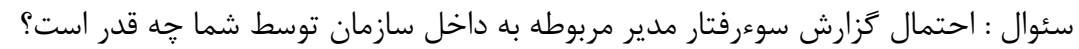

\begin{tabular}{|c|c|c|c|c|}
\hline خيلى زياد & زياد & متوسط & كم & خيلى كم \\
\hline$\Delta$ & f & $r$ & r & 1 \\
\hline
\end{tabular}


مقياس حاضر شامل برخى وازهها است كه احساسات و هيجانـات متفـاوت را توصسيف مسى كنــد.

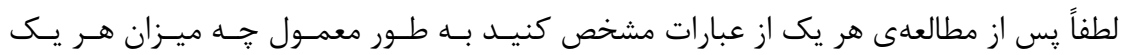

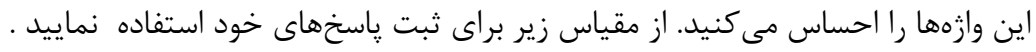

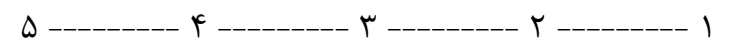

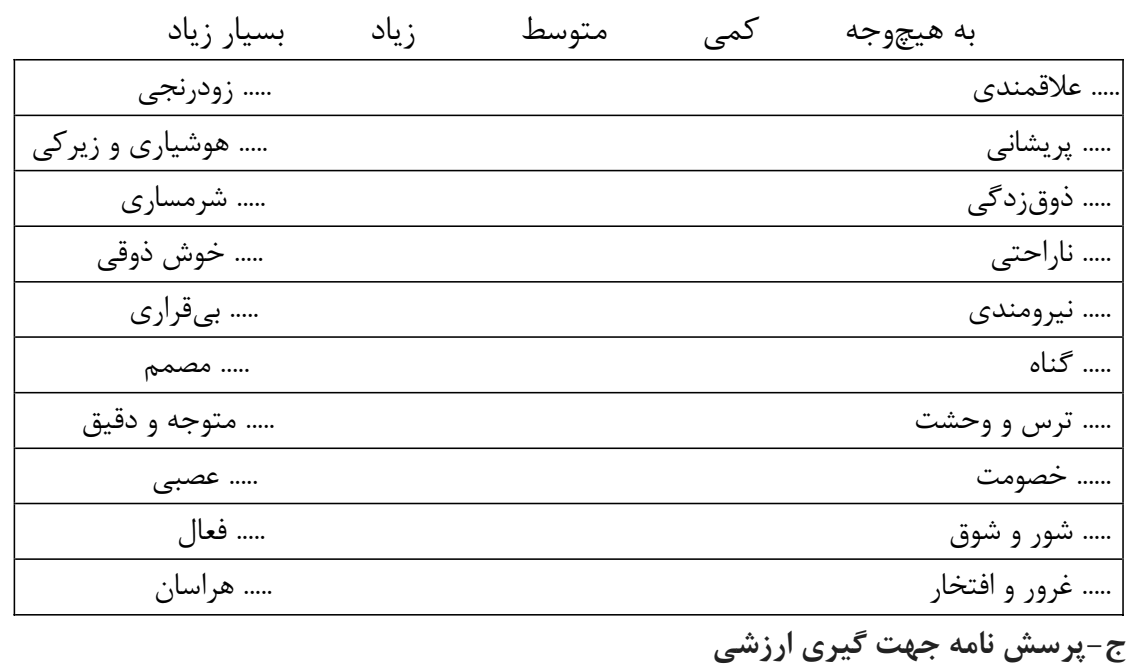

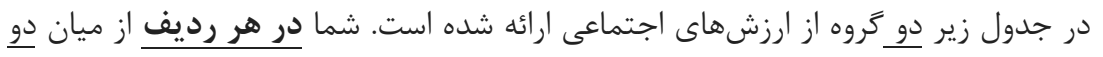

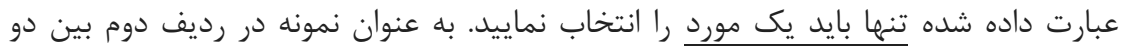

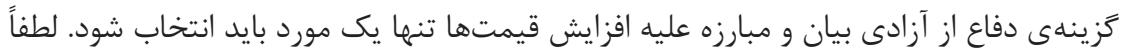

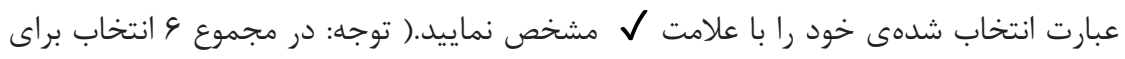
شما وجود دارد)

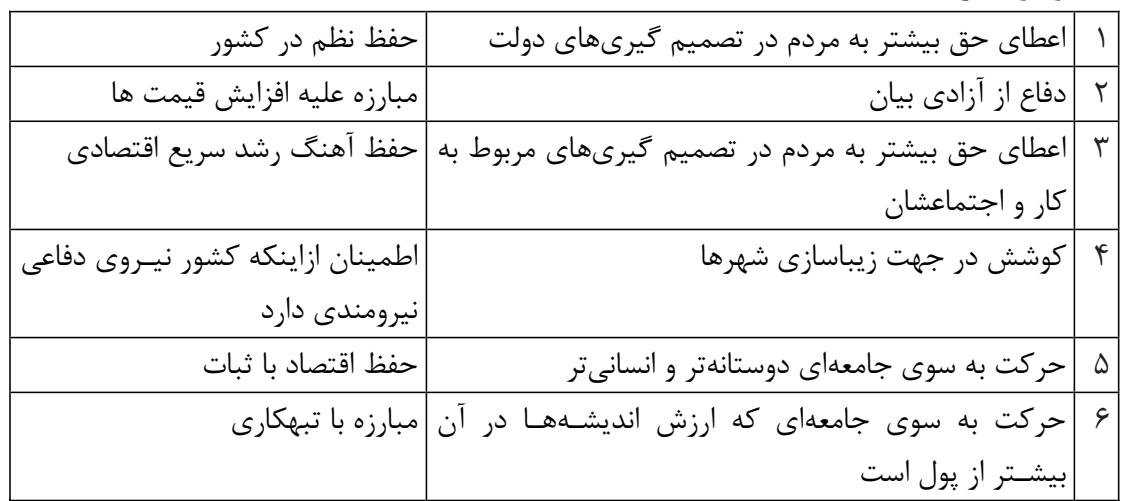




\begin{tabular}{|c|c|c|c|c|c|c|}
\hline \multicolumn{7}{|c|}{ د - پيرسش نامه انصاف } \\
\hline $\begin{array}{l}\frac{b}{3} \\
\frac{3}{2} \\
\frac{1}{2} \\
\frac{1}{2}\end{array}$ & $\frac{2}{i}$ & 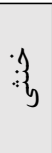 &. $\int_{2}^{3}$ & 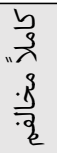 & خزاره ها & \\
\hline & & & & & بيشترين مزايا را دريافت كمتر در محل كارم را ترجيح مى دهم، اما انتظار دارم & 1 \\
\hline & & & & & يك گروه در محل كارم بيشترين رضايت را زمانى دارم كه جز كوجكى از & r \\
\hline & & & & & هنى كنمامى كه سر كار هستم، به راههايى براى ترك محل كارم فكر & r \\
\hline & & & & & خيلى كمتر از حد انتم راهى براى ترى محل كارم يِيدا كنه، تلاش خواهم كرد & is \\
\hline & & & & & زياد بخيرمى كار براى من رضايت بخش است كه بتوانم در محيط كار جيزى & $\Delta$ \\
\hline & & & & & كارمند هوشمند كسى است كه بيشترين مزاياى ممكن را كه در & 4 \\
\hline & & & & & 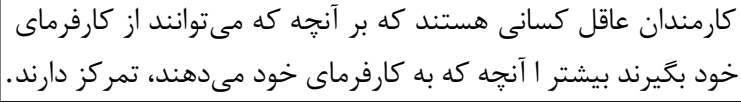 & V \\
\hline & & & & & وظقيى من وظايف خودم را انجام مى دهم به كارمندان ديخرى كه هنوز & $\Lambda$ \\
\hline & & & & & من حتى اتر حقوق و مزاياى كمترى دريافت نمايم، باز هم براى كار & 9 \\
\hline & & & & & آنر مجبور باشم تمام ايام در محل كارم به سختى كار كنم، احتمالاً & 1 . \\
\hline & & & & & احرداخت مس شى شنهم مجبور هستم بيش از آنجه كه در محل كار به من & 11 \\
\hline & & & & & در سر كار بيشترين توجه من به اين است كه آيا بهترين كارى كه & $1 T$ \\
\hline & & & & & 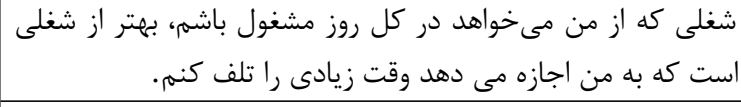 & 14 \\
\hline & & & & & نار احتى مى كارم وقتى كنه كار اندكى براى انجام دادن وجود دارد، احساس & if \\
\hline
\end{tabular}




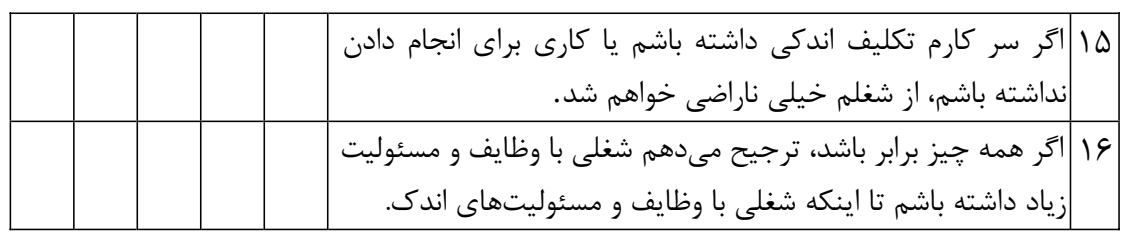

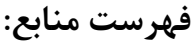

امانى، كوروش؛ نيكومرام، هاشم؛ بنى مهل، بهمن.( 99 (1)، عواطف فردى و ترديد حرفه اى

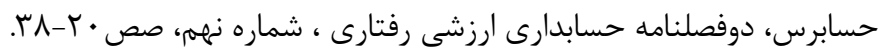

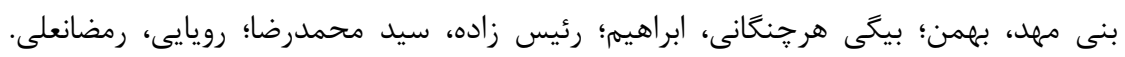

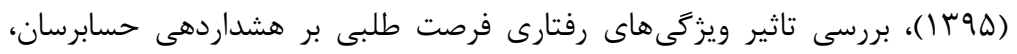

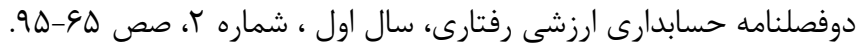

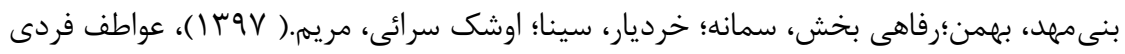

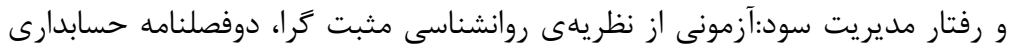

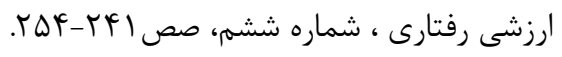

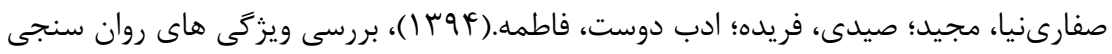

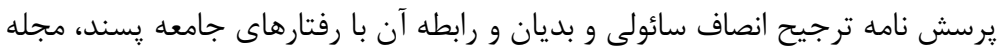

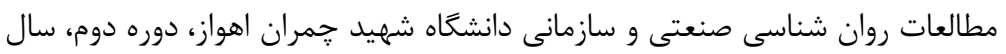

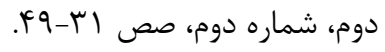

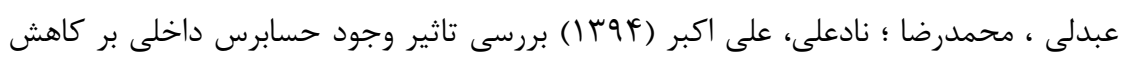

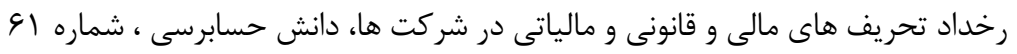
صص مركز يزوهش هاى مجلس شوراى اسلامى (•وبا()قانون ارتقاء سلامت نظام ادارى و مقابله با https://rc.majlis.ir/fa/law/show/802617 فساد آنقاد

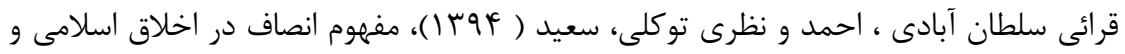

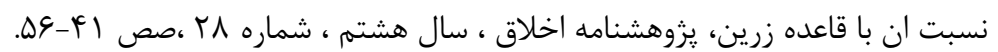

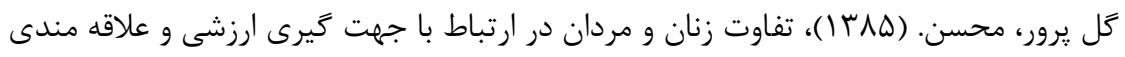

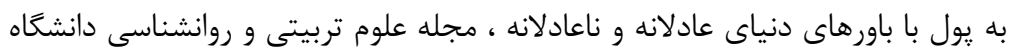

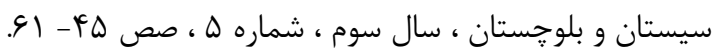

Ahmad, Z., and D. Taylor.2009. Commitment to independence by internal auditors: The effects of role ambiguity and role conflict. Managerial Auditing Journal 24 (9): 899-925. 
Andon, P., C. Free, R. Jidin, G. S. Monroe, and M. J. Turner.2016. The impact of financial incentives and perceptions of seriousness on whistleblowing intention. Journal of Business Ethics [in press].

Andon,P., C.Free, R. Jidin, G.Monroe, M. Turner. 2018. The Impact of Financial Incentives and Perceptions of Seriousness on Whistleblowing Intention. J Bus Ethics 151: 165-178

Armstrong, B., J.P.Nitschke, U.Bilash, and D.C. Zuroff. 2020. An affect in its own right: Investigating the relationship of social safeness with positive and negative affect, Personality and Individual Differences(Forthcoming).https://doi.org/10.1016/j.paid.2019.109670.

Brennan, N., and J. Kelly. 2007. A study of whistleblowing among trainee auditors. The British Accounting Review 39(1): 61-87.

Behrens, A. 2015. The Impact of Culture on the Efficacy and Fairness of Whistle-blowing: A Contrast Between Brazil and the United States ,Thunderbird International Business Review 57(5) : 359-365.

Chiasson, M., H. G Johnson, and J. R. Byington. 1995. Blowing the whistle: Accountants in industry. CPA Journal 65(2): 24-27.

Curtis, M. 2006. Are audit-related ethical decisions dependent upon mood? Journal of Business Ethics 68(2): 191-209.

Dandekar, N. 1990. Contrasting consequences: Bringing charges of sexual harassment compared with other cases of whistleblowing. Journal of Business Ethics 9(2): 151-158.

Deloitte Forensic Center. 2010. Whistleblowing and the new race to report: Deloitte Touche Tohmatsu.

Dewa, D., G.Yudha, M.Rizal. 2018. Gender, Religiosity,Positive Mood and Whistle-blowing Intention, RJOAS, 1(73): 5-18.

Dhamija, S., and S.Rai. 2018. Role of retaliation and value orientation in whistleblowing intentions, Asian Journal of Business Ethics 7(3) :3752

Dungana, J.A., L.Young, and A.Waytz. 2019. The power of moral concerns in predicting whistle-blowing decisions, Journal of Experimental Social Psychology ,85:1-12

Dworkin, T. M., and M. S. Baucus.1998. Internal versus external whistleblowers: A comparison of whistleblowing processes. Journal of Business Ethics, 17(12):1281-1298.

Feldman, G., M. M. Chao, J. L.Farh, and A. Bardi. 2015. The motivation and inhibition of breaking the rules: Personal values structures predict unethicality. Journal of Research in Personality,59(11): 69-80.

Feldman, Y.,and O. Lobel. 2010. The incentives matrix: The comparative effectiveness of rewards, liabilities, duties, and protections for reporting illegality. Texas Law Review, 88(6): 1151-1211. 
Grant, C. 2002. Whistle blowers: Saints of secular culture. Journal of Business Ethics, 39(4): 391-399.

Inglehart, R. 1990. Culture Shift in Advanced Industrial Society. Princeton, NJ Princeton University Press.

Inglehart, R., and W.E.Baker. 2000. Modernization, cultural change, and the persistence of traditional values. American Sociological Review 65: $19-51$.

King, G. 2000.The implications of differences in cultural attitudes and styles of communication on peer reporting behaviour. Cross-Cultural Management, 7(2): 11-17.

KPMG. 2010. Fraud and misconduct survey 2010: Australia and New Zealand.

Liyanarachchi, G. A., and R. Adler. 2011. Accountants' whistle-blowing intentions: The impact of retaliation, age, and gender. Australian Accounting Review, 21(2): 167-182.

Miethe, T. D., and J. Rothschild. 1994. Whistleblowing and the control of organizational misconduct. Sociological Inquiry, 64(3): 322-347.

Nayir, D.Z., and C.Herzig. 2012 Value Orientations as Determinants of Preference for External and Anonymous Whistle-blowing, Journal of Business Ethics, 107(1):197-213.

Near, J. P., M. T Rehg, J. R.Van Scotter, and M. P. Miceli. 2004. Does type of wrongdoing affect the whistle-blowing process? Business Ethics Quarterly, 14(2): 219-242.

Nisar, T., G. Prabhakar,and M. Torchia.2019. Whistleblowing: When do employees act to 'blow the whistle'? Organizational Dynamics Vol. 48(1): 44-49.

Park, H., and J. Blenkinsopp. 2009. Whistleblowing as planned behavior-A survey of South Korean police officers. Journal of Business Ethics, 85(4): 545-556.

Park, H., J.Blenkinsopp, M. K.Oktem, and U.Omurgonulsen. 2008. Cultural orientation and attitudes toward different forms of whistleblowing: A comparison of South Korea, Turkey, and the U.K. Journal of Business Ethics, 82(4):929-939.

Pohling, R., D.Bzdok, M.Eigenstetter, S.Stumpf, and A. Strobel.2016. What is ethical competence? The role of empathy, personal values, and the five-factor model of personality in ethical decision-making. Journal of Business Ethics, 137(3): 449-474.

Price, A. R. 1998. Anonymity and pseudonymity in whistleblowing to the US Office of Research Integrity. Academic Medicine, 73(5):467-472.

Reckers-Sauciuc, A. K., and D. J. Lowe. 2010. The influence of dispositional affect on whistle-blowing. Advances in Accounting, 26(2): 259-269. 
Sauley, K. S., and A. G. Bedeian. 2000. Equity sensitivity: Construction Construction of a measure and examination of its psychometric properties . Journal of Management, 26(5): 885-910.

SEC.gov. 2014. SEC awards $\$ 875,000$ to two whistleblowers who aided agency investigation.

Available at: https://www.sec.gov/news/pressrelease/detail/pressrelease/13705419 80219.

SEC.gov. 2015. SEC pays more than $\$ 3$ million to whistleblower. Available at: Https://www.sec.gov/news/pressrelease/2015-150.html.

Seifert, D.L., W.W. Stammerjohan, and R.B. Martin. 2014. Trust, Organizational Justice, and Whistleblowing: A Research Note. Behavioral Research in Accounting, 26 (1): 157-168.

Seifert, D. L., J. T. Sweeney, J.Joireman, and J. M. Thornton. 2010. The influence of organizational justice on accountant whistleblowing Accounting. Organizations and Society, 35(7):707-717.

Soni, F., W. Maroun, and N. Padia. 2015. Perceptions of Justice as a Catalyst for Whistle-Blowing by Trainee Auditors in South Africa", Meditari Accountancy Research, 23 (1):118-140.

Syahrul, A. 2011. Internal auditor and internal whistleblowing intentions : a study of organisational, individual, situational and demographic factors. Retrieved from http://ro.ecu.edu.au/theses/152.

Tang TLP, Chiu RK .2003. Income, money ethic, pay satisfaction, commitment, and unethical behavior: is the love to money the root of evil for Hong Kong employees? Journal of Business Ethics 46: 13-30.

Valentinea ,S., and L.Godkin. 2019. Moral intensity, ethical decision making, and whistleblowing intention, Journal of Business Research, 98(2) $227-288$

Verschuuren, P. 2020. Whistleblowing determinants and the effectiveness of reporting channels in the international sports sector, Sport Management Review , Forthcoming.

Watson,D., L.A.Clark, and g. Carey. 1988. Positive and negative affectivity and their relation to anxiety and depression disorers, journal of personality and social psychology 54: $1063-1070$.

Watts,L. L., M.R. Buckley.2017. A Dual-Processing Model of Moral Whistleblowing in Organizations, Journal of Business Ethics vol. 146 : 669-683

Waytz, A., J .Dungan, and L.Young. 2013. The whistleblower's dilemma and the fairness - loyalty tradeoff. J Exp Soc Psychol, 49:1027- 1033.

$\mathrm{Xu}, \mathrm{Y}$., and D. Ziegenfuss. 2008. Reward systems, moral reasoning, and internal auditors' reporting wrongdoing. Journal of Business Psychology 22(4): 323-331. 


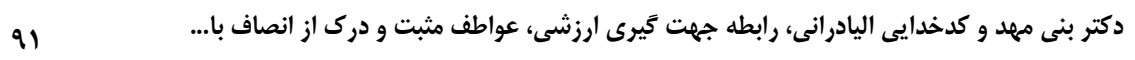

Young, R. 2016. An Empirical Examination of Psychological Climate and Internal Disclosure Policy Compliance, Advances in Accounting Behavioral Research,19(2):127-154

Zhang, J., R.Chiu, and L. Wei .2009. Decision-making process of internal whistleblowing behavior in China: Empirical evidence and implications. Journal of Business Ethics, 88(SUPPL.1): 25-41.

Zolotoy,L., D.O'Sullivan, M.Seo, and M. Veeraraghava. 2020. Mood and Ethical Decision Making: Positive Affect and Corporate Philanthropy, Journal of Business Ethics, (Forthcoming) https://doi.org/10.1007/s10551-020-04432-5. 